ARTICLE

https://doi.org/10.1038/s41467-019-11102-2

\title{
A safe and non-flammable sodium metal battery based on an ionic liquid electrolyte
}

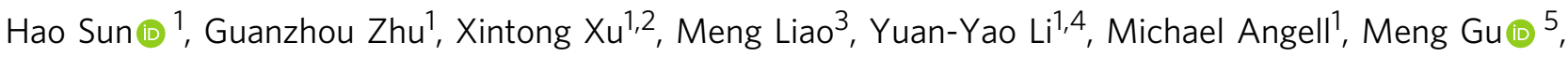 \\ Yuanmin Zhu ${ }^{5,6}$, Wei Hsuan Hung (1) 1,7,8, Jiachen Li ${ }^{1}$, Yun Kuang ${ }^{1,9}$, Yongtao Meng ${ }^{1}$, Meng-Chang Lin ${ }^{10}$, \\ Huisheng Peng ${ }^{3} \&$ Hongjie Dai ${ }^{1}$
}

Rechargeable sodium metal batteries with high energy density could be important to a wide range of energy applications in modern society. The pursuit of higher energy density should ideally come with high safety, a goal difficult for electrolytes based on organic solvents. Here we report a chloroaluminate ionic liquid electrolyte comprised of aluminium chloride/1-methyl-3-ethylimidazolium chloride/sodium chloride ionic liquid spiked with two important additives, ethylaluminum dichloride and 1-ethyl-3-methylimidazolium bis(fluorosulfonyl)imide. This leads to the first chloroaluminate based ionic liquid electrolyte for rechargeable sodium metal battery. The obtained batteries reached voltages up to $\sim 4 \mathrm{~V}$, high Coulombic efficiency up to $99.9 \%$, and high energy and power density of $\sim 420 \mathrm{Wh} \mathrm{kg}^{-1}$ and $\sim 1766 \mathrm{~W} \mathrm{~kg}^{-1}$, respectively. The batteries retained over $90 \%$ of the original capacity after 700 cycles, suggesting an effective approach to sodium metal batteries with high energy/ high power density, long cycle life and high safety.

\footnotetext{
${ }^{1}$ Department of Chemistry, Stanford University, Stanford, CA 94305, USA. ${ }^{2}$ School of Aerospace Engineering, Tsinghua University, Beijing 100084, China.

${ }^{3}$ State Key Laboratory of Molecular Engineering of Polymers, Department of Macromolecular Science, and Laboratory of Advanced Materials, Fudan University, Shanghai 200438, China. ${ }^{4}$ Department of Chemical Engineering, National Chung Cheng University, Chia-Yi 62102, Taiwan. ${ }^{5}$ Department of Materials Science and Engineering, Southern University of Science and Technology, Shenzhen, Guangdong 518055, China. ${ }^{6}$ Academy for Advanced Interdisciplinary Studies, Southern University of Science and Technology, Shenzhen 518055, China. ${ }^{7}$ Department of Materials Science and Engineering, Feng Chia University, Taichung 40724, Taiwan. ${ }^{8}$ Institute of Materials Science and Engineering, National Central University, Taoyuan 32001 , Taiwan. ${ }^{9}$ State Key laboratory of Chemical Resource Engineering and Beijing Advanced Innovation Center for Soft Matter Science and Engineering, Beijing University of Chemical Technology, Beijing 100029, China. ${ }^{10}$ College of Electrical Engineering and Automation, Shandong University of Science and Technology, Qingdao 266590, China. Correspondence and requests for materials should be addressed to H.D. (email: hdai@stanford.edu)
} 
igh-energy rechargeable battery systems have been actively pursued for a wide range of applications from portable electronics to grid energy storage and electric automotive industry $^{1-6}$. At higher energies, battery safety becomes increasingly important, evident from high-profile battery fires/explosion accidents in recent years. Rechargeable batteries using flammable organic electrolytes always risk fire/explosion hazards when short circuit or thermal runaway happens, setting a bottleneck in battery design/engineering and requiring innovations of next-generation battery systems with intrinsically higher safety ${ }^{7,8}$. For organic electrolytes various strategies have been investigated to mitigate the safety concerns, including the use of voltage or temperaturesensitive separators ${ }^{9-11}$ and overcharge protection additives ${ }^{12}$. Developing new electrolyte systems that are intrinsically nonflammable has also been actively pursued ${ }^{13-15}$. In particular, room temperature ionic liquids (ILs) have been widely explored as promising candidates due to their non-flammable nature ${ }^{16-18}$. Among them, ILs comprised of $\mathrm{AlCl}_{3}$ and 1-ethyl-3methylimidazolium chloride $([\mathrm{EMIm}] \mathrm{Cl})$ are a classical chloroaluminate based electrolyte system with many desired properties including non-flammability, non-volatility, low viscosity, high conductivity, and high thermal stability and chemical inertness ${ }^{17,19}$. In this electrolyte, $\mathrm{AlCl}_{3}$ complexes with the $\mathrm{Cl}$ ion from [EMIm]Cl to produce $\mathrm{AlCl}_{4}{ }^{-}$and $\mathrm{EMIm}^{+}$, and any excess $\mathrm{AlCl}_{3}$ converts a portion of $\mathrm{AlCl}_{4}^{-}$into $\mathrm{Al}_{2} \mathrm{Cl}_{7}^{-}$, resulting in the coexistence of $\mathrm{AlCl}_{4}{ }^{-}$and $\mathrm{Al}_{2} \mathrm{Cl}_{7}^{-}$:

$$
\begin{gathered}
\mathrm{AlCl}_{3}+[\mathrm{EMIm}] \mathrm{Cl} \rightarrow \mathrm{AlCl}_{4}^{-}+[\mathrm{EMIm}]^{+} \\
\mathrm{AlCl}_{4}^{-}+\mathrm{AlCl}_{3} \rightarrow \mathrm{Al}_{2} \mathrm{Cl}_{7}^{-}
\end{gathered}
$$

The $\mathrm{AlCl}_{3} /[\mathrm{EMIm}] \mathrm{Cl}$-based ILs have been used as electrolytes for rechargeable metal batteries ${ }^{20,21}$. An example was rechargeable aluminum-graphite battery developed by our group and others with fast and highly reversible $\mathrm{AlCl}_{4}{ }^{-}$intercalation/deintercalation into graphite positive electrode, and $\mathrm{Al}_{2} \mathrm{Cl}_{7}{ }^{-}$plating and stripping on Al negative electrode ${ }^{20}$. Nevertheless, it is desirable to develop higher voltage and higher energy density battery systems utilizing chloroaluminate IL electrolytes. A promising strategy is replacing $\mathrm{Al}$ by more reactive metal negative electrodes with lower standard electrode potentials such as sodium and lithium, which could raise the battery voltage and allow the use of well-established positive electrode materials with higher energy densities. Indeed, researchers have been pursuing this direction since almost 30 years ago. In as early as 1990, Melton et al. reported the first buffered $\mathrm{AlCl}_{3} /[\mathrm{EMIm}] \mathrm{Cl}$ IL system by adding $\mathrm{NaCl}$, eliminating $\mathrm{Al}_{2} \mathrm{Cl}_{7}{ }^{-}$and introducing $\mathrm{Na}$ ions into the electrolyte ${ }^{22}$ via

$$
\mathrm{Al}_{2} \mathrm{Cl}_{7}^{-}+\mathrm{NaCl} \rightarrow 2 \mathrm{AlCl}_{4}^{-}+\mathrm{Na}^{+}
$$

Thus far, however, reversible and stable deposition and stripping/oxidation of $\mathrm{Na}$ metal in buffered $\mathrm{AlCl}_{3} /[\mathrm{EMIm}] \mathrm{Cl}$ ILs towards rechargeable $\mathrm{Na}$ batteries have been hindered, with or without the use of a variety of electrolyte additives such as $\mathrm{HCl}^{23}$, [EMIm] $\mathrm{HCl}_{2}{ }^{24,25}$, triethanolamine hydrochloride ${ }^{26}$ and thionyl chloride $^{27}$. These additives can stabilize $\mathrm{Na}$ redox to limited degrees, affording Coulombic efficiencies (CEs) of $65-94 \%$ for $\mathrm{Na}$ plating/stripping $23-27$. For instance, the $\mathrm{CE}$ record of reversible $\mathrm{Na}$ redox was $94 \%$ achieved with $\sim 6$ Torr $\mathrm{HCl}$ added to $\mathrm{NaCl}$ buffered $\mathrm{AlCl}_{3} /[\mathrm{EMIm}] \mathrm{Cl}=\sim 1.7$ IL at $6.4 \mathrm{~mA} \mathrm{~cm}^{-2}$, but it rapidly decayed at a lower current density ${ }^{23}$. None of the chloroaluminate ILs could afford multicycle Na plating/stripping with sufficiently high CE to pair with sodium positive electrode for $\mathrm{Na}$ battery cells ${ }^{17}$.

Here we present an ionic liquid electrolyte based on $\mathrm{NaCl}$-buffered $\mathrm{AlCl}_{3} /$ [EMIm] Cl for safe and high energy $\mathrm{Na}$ batteries. Two electrolyte additives at the 1 to $4 \%$ by mass level i.e., ethylaluminum dichloride $\left(\mathrm{EtAlCl}_{2}\right)$ and 1-ethyl-3methylimidazolium bis(fluorosulfonyl) imide ([EMIm]FSI) are key to stabilizing SEI on sodium negative electrode for reversible $\mathrm{Na}$ plating/stripping. In a $\mathrm{Na} / \mathrm{Pt}$ cell containing this IL electrolyte, a CE of $\sim 95 \%$ is reached at $0.5 \mathrm{~mA} \mathrm{~cm}^{-2}$ over $\sim 100$ reversible $\mathrm{Na}$ plating/stripping cycles. With the optimized IL electrolyte, we pair $\mathrm{Na}$ negative electrode with sodium vanadium phosphate (NVP) and sodium vanadium phosphate fluoride (NVPF) based positive electrodes to afford high discharge voltage up to $\sim 4 \mathrm{~V}$, high CEs up to $99.9 \%$, and maximal energy and power density of $420 \mathrm{Wh} \mathrm{kg}^{-1}$ and $1766 \mathrm{~W} \mathrm{~kg}^{-1}$, respectively based on active material mass of positive electrode. In addition, more than $90 \%$ of the original capacity is retained after over 700 cycles. Solidelectrolyte interphase (SEI) analysis reveals SEI compositions including $\mathrm{NaCl}, \mathrm{Al}_{2} \mathrm{O}_{3}$ and $\mathrm{NaF}$ derived from the reactions between $\mathrm{Na}$ and the anions in the IL electrolyte. The results shed light on future electrolyte and SEI design towards practical sodium metal batteries with high safety and high energy/power densities.

\section{Results}

Properties of $\mathrm{NaCl}$-buffered $\mathrm{AlCl}_{3} /[\mathrm{EMIm}] \mathrm{Cl}$ ionic liquid. Preparation of IL electrolyte (see "Methods" section) started by mixing anhydrous $\mathrm{AlCl}_{3}$ and [EMIm] Cl at a molar ratio of 1.5:1 to form an acidic room-temperature IL $\left(\mathrm{AlCl}_{3} /[\mathrm{EMIm}] \mathrm{Cl}=1.5\right)$, followed by buffering to neutral with excess $\mathrm{NaCl}$ and then adding $1 \mathrm{wt} \% \mathrm{EtAlCl}_{2}$ and $4 \mathrm{wt} \%$ [EMIm]FSI to afford the final $\mathrm{NaCl}$-buffered chloroaluminate IL electrolyte (referred as 'buffered Na-Cl-IL electrolyte') (Fig. 1a). Raman spectroscopy was performed to probe the evolution of $\mathrm{AlCl}_{4}{ }^{-}$and $\mathrm{Al}_{2} \mathrm{Cl}_{7}{ }^{-}$species in the IL at different stages (Fig. 1b). Both $\mathrm{AlCl}_{4}{ }^{-}$and $\mathrm{Al}_{2} \mathrm{Cl}_{7}{ }^{-}$ peaks were observed in the starting acidic IL with $\mathrm{AlCl}_{3} /[\mathrm{EMIm}]$ $\mathrm{Cl}=1.5$. After $\mathrm{NaCl}$ buffering of the electrolyte to neutral, the $\mathrm{Al}_{2} \mathrm{Cl}_{7}{ }^{-}$peaks at 309 and $430 \mathrm{~cm}^{-1}$ disappeared while the $\mathrm{AlCl}_{4}{ }^{-}$ peak at $350 \mathrm{~cm}^{-1}$ strengthened, indicating the conversion of $\mathrm{Al}_{2} \mathrm{Cl}_{7}{ }^{-}$to $\mathrm{AlCl}_{4}{ }^{-}$by $\mathrm{NaCl}$ on the basis of equation (3). Subsequent addition of $1 \mathrm{wt} \% \mathrm{EtAlCl}_{2}$ resulted in a noticeable further enhancement of the $\mathrm{AlCl}_{4}{ }^{-}$peak. This was attributed to reactions of $\mathrm{EtAlCl}_{2}$ with trace amounts of protons and undissolved $\mathrm{NaCl}$ in the buffered $\mathrm{AlCl}_{3} /[\mathrm{EMIm}] \mathrm{Cl}=1.5 \mathrm{IL}$ with the generation of $\mathrm{AlCl}_{4}^{-}, \mathrm{C}_{2} \mathrm{H}_{6}$ and $\mathrm{Na}^{+}$via ${ }^{28}$ :

$$
\mathrm{EtAlCl}_{2}+\mathrm{H}^{+}+2 \mathrm{NaCl} \rightarrow \mathrm{C}_{2} \mathrm{H}_{6}(\mathrm{~g})+\mathrm{AlCl}_{4}^{-}+2 \mathrm{Na}^{+}
$$

No obvious change in the Raman spectrum of chloroaluminate species was observed after the addition of $4 \mathrm{wt} \%$ [EMIm]FSI (Fig. 1b). The final buffered electrolyte (named buffered $\mathrm{Na}-\mathrm{Cl}-\mathrm{IL}$ hereon) was comprised of $\mathrm{Na}^{+}, \mathrm{AlCl}_{4}{ }^{-}, \mathrm{EMIm}^{+}$ and $\mathrm{FSI}^{-}$with $\mathrm{Na}^{+}$and $\mathrm{FSI}^{-}$molar concentration of $\sim 1.76 \mathrm{M}$ and $\sim 0.2 \mathrm{M}$, respectively.

An important property of the buffered $\mathrm{Na}-\mathrm{Cl}-\mathrm{IL}$ was its high ionic conductivity of $\sim 9.2 \mathrm{mS} \mathrm{cm}^{-1}$ at $25^{\circ} \mathrm{C}$, which was $2-20$ times higher than those of previously reported IL electrolytes based on bulky cations (e.g., $N$-butyl- $N$-methylpyrrolidinium and $N$-propyl- $N$-methylpyrrolidinium) for $\mathrm{Na}$ batteries $^{29-32}$ (Fig. 1c). The ionic conductivity was comparable to conventional organic electrolytes, for example, $\sim 6.5 \mathrm{mS} \mathrm{cm}^{-1}$ of $1 \mathrm{M} \mathrm{NaClO}$ in propylene carbonate (PC), and $6.35 \mathrm{mS} \mathrm{cm}^{-1}$ of $1 \mathrm{M} \mathrm{NaClO}_{4}$ in ethylene carbonate/diethyl carbonate (EC/DEC, 1:1 by weight) ${ }^{33}$. The thermal stability of our buffered $\mathrm{Na}-\mathrm{Cl}-\mathrm{IL}$ electrolyte was compared with a conventional organic electrolyte $1 \mathrm{M} \mathrm{NaClO}_{4}$ in EC/DEC (1:1 by vol) with $5 \mathrm{wt} \%$ FEC additive by thermogravimetric analysis (TGA) (Fig. 1d). The organic electrolyte showed a rapid weight loss above $132^{\circ} \mathrm{C}$, and lost $\sim 85 \%$ of the original weight at $230{ }^{\circ} \mathrm{C}$ due to decomposition of the carbonate solvents 
a

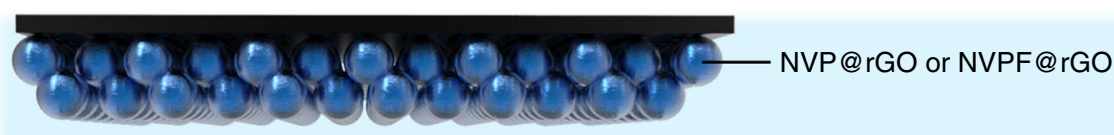

$\mathrm{NaCl}$-buffered $\mathrm{AlCl}_{3} /[\mathrm{EMIm}] \mathrm{Cl}=1.5$ ionic liquid

$\mathrm{NaF}, \mathrm{Al}_{2} \mathrm{O}_{3}$ and $\mathrm{NaCl}$-based

with 1 wt\% $\mathrm{EtAlCl}_{2}$ and 4 wt\% [EMIm]FSI solid electrolyte interphase

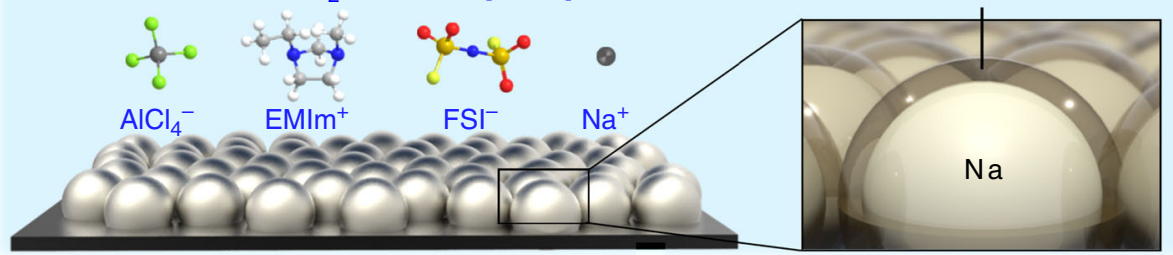

b

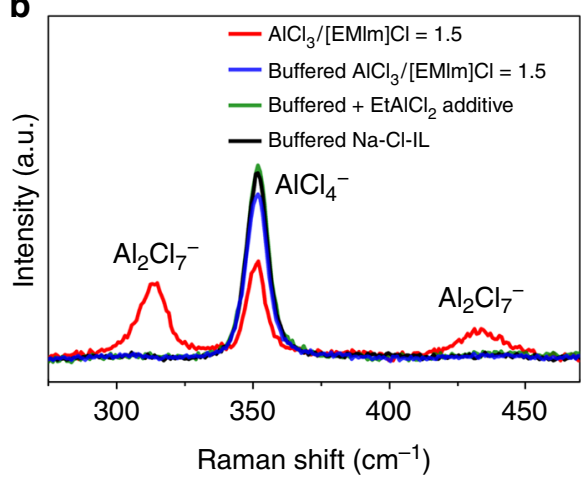

d

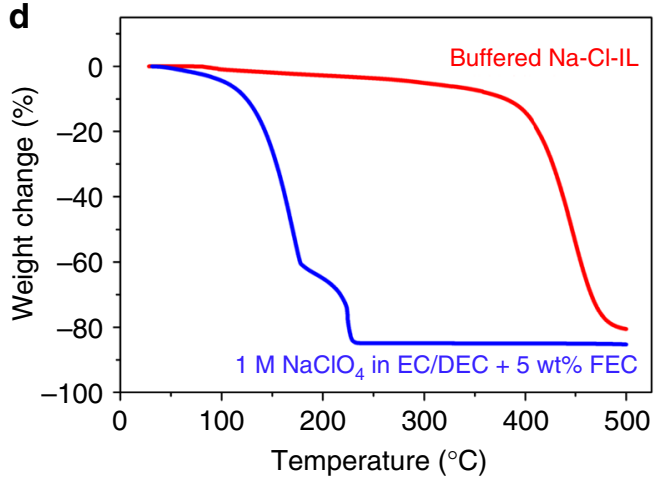

C

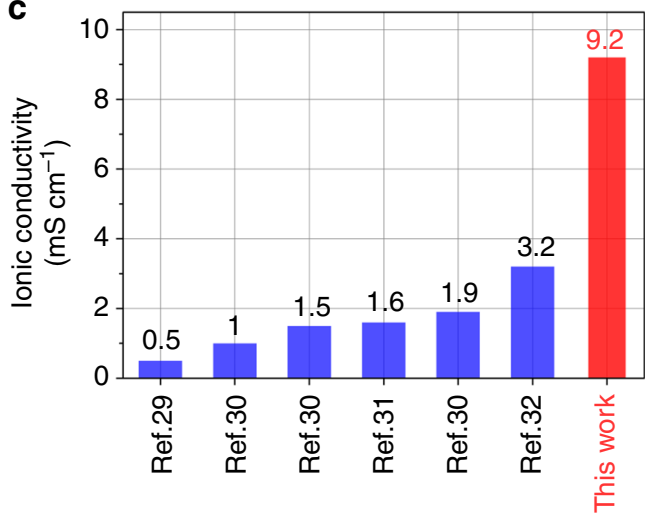

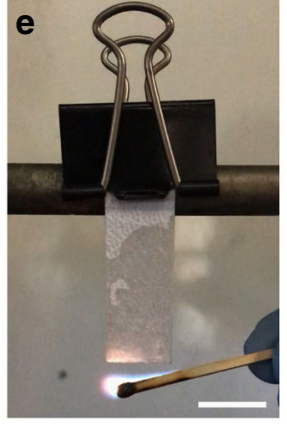

IL electrolyte

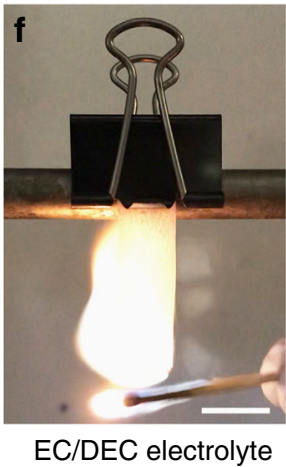

Fig. 1 Properties of the buffered $\mathrm{Na}-\mathrm{Cl}-\mathrm{IL}$ electrolyte. a Schematic illustration of the battery configuration and electrolyte composition of the IL electrolyte. b Raman spectra of ILs based on $\mathrm{AlCl}_{3} /[\mathrm{EMIm}] \mathrm{Cl}=1.5$ with different additives. $\mathbf{c}$ lonic conductivities of buffered $\mathrm{Na}-\mathrm{Cl}$-IL and other IL-based electrolytes for $\mathrm{Na}$ batteries at $25^{\circ} \mathrm{C}^{29-32}$. d-f Thermal stability (d) and flammability tests using buffered $\mathrm{Na}-\mathrm{Cl}-\mathrm{IL}(\mathbf{e})$ and conventional 1.0 M NaClO ${ }_{4}$ in EC:DEC (1:1 by vol) with $5 \mathrm{wt} \% \mathrm{FEC}$ electrolytes (f). Scale bars in (e, $\mathbf{f}), 1 \mathrm{~cm}$

in this temperature range. In comparison, the buffered $\mathrm{Na}-\mathrm{Cl}-\mathrm{IL}$ showed a much better thermal stability without severe weight loss until $\sim 400^{\circ} \mathrm{C}$. The non-flammable nature of the buffered $\mathrm{Na}-\mathrm{Cl}-\mathrm{IL}$ electrolyte was confirmed when it was soaked into a porous separator and contacted with flame (Fig. 1e and Supplementary Movie 1) without causing fire. In contrast, the organic carbonate electrolyte easily caught fire and burned immediately (Fig. If and Supplementary Movie 2).

Electrochemistry of $\mathrm{Na}-\mathrm{Cl}-\mathrm{IL}$ electrolyte. In a $\mathrm{Na}$ vs. carbonfibre-paper cell containing the buffered $\mathrm{Na}-\mathrm{Cl}-\mathrm{IL}$ electrolyte, linear sweep voltammetry scan was performed (Fig. 2a) and revealed a pair of sodium redox peaks on the cathodic side and no obvious electrolyte decomposition was observed until $\sim 4.56 \mathrm{~V}$ on the anodic side, indicating high electrochemical stability of the electrolyte for high-voltage sodium battery systems. Sodium reduction/oxidation peaks were clearly observed in cyclic voltammetry $(\mathrm{CV})$ with a $\mathrm{Pt}$ working electrode, a $\mathrm{Na}$ reference and counter electrode in buffered $\mathrm{Na}-\mathrm{Cl}-\mathrm{IL}$ electrolyte, showing reversible $\mathrm{Na}$ plating and stripping on Pt (Fig. 2b). In striking contrast, redox peaks were completely missing in buffered electrolyte without [EMIm]FSI additive, suggesting its critical role of stabilizing Na plating/stripping (Fig. 2c). Galvanostatic chargedischarge test investigated $\mathrm{Na}$ plating/stripping on $\mathrm{Pt}$ in buffered $\mathrm{Na}-\mathrm{Cl}-\mathrm{IL}$ electrolyte at a plating current density of $0.5 \mathrm{~mA} \mathrm{~cm}^{-2}$ for $30 \mathrm{~min}$. The CE increased from $\sim 72$ to $\sim 91 \%$ during the first 5 cycles for SEI formation and then reached $\sim 95 \%$, which is a new record of $\mathrm{Na}$ redox for both buffered chloroaluminate ILs and any other ionic liquids based on different cations (including benzyldimethylethylammonium, butyldimethylpropylammonium, trimethylhexylammonium, dibutyldimethylammonium and $N$-butyl- $N$-methylpyrrolidinium) and anions (including FSI and TFSI) ${ }^{17,34-36}$ (Fig. 2d, TFSI represents bis (trifluoromethanesulfonyl)imide). Reversible Na plating/stripping 
a

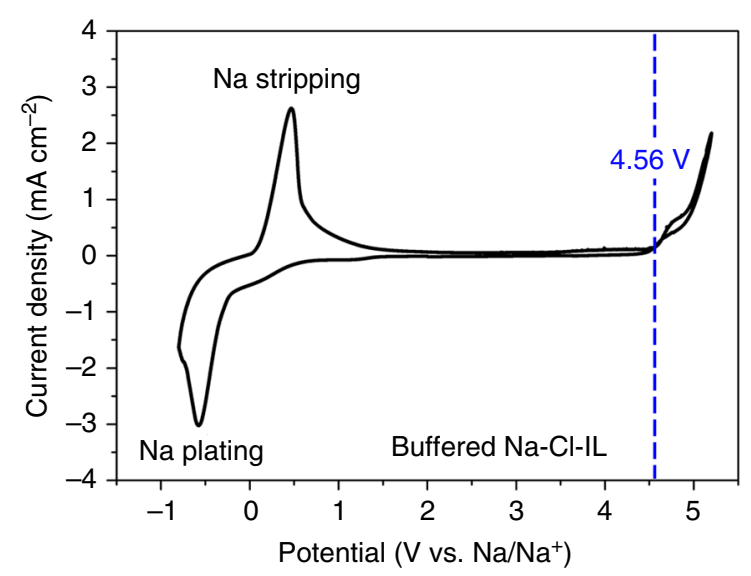

c

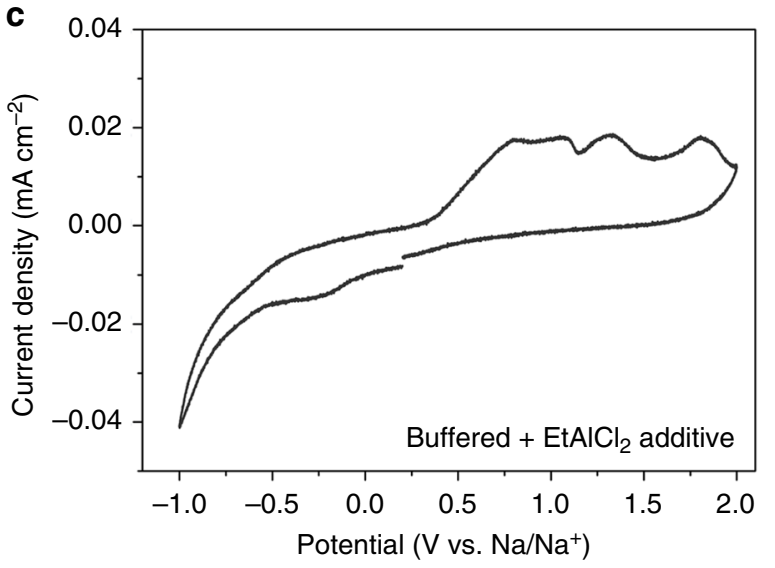

b

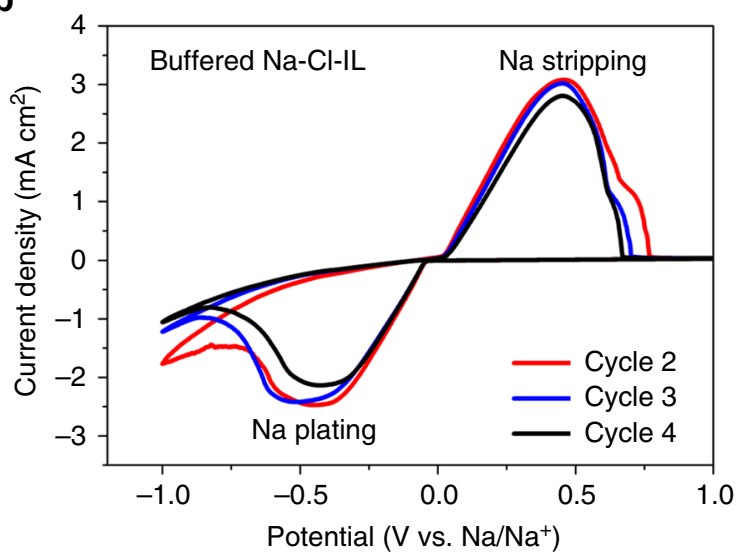

d

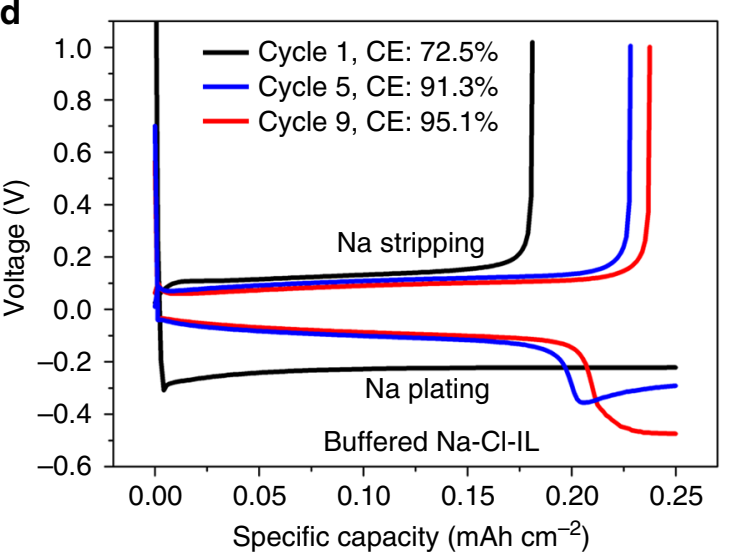

e

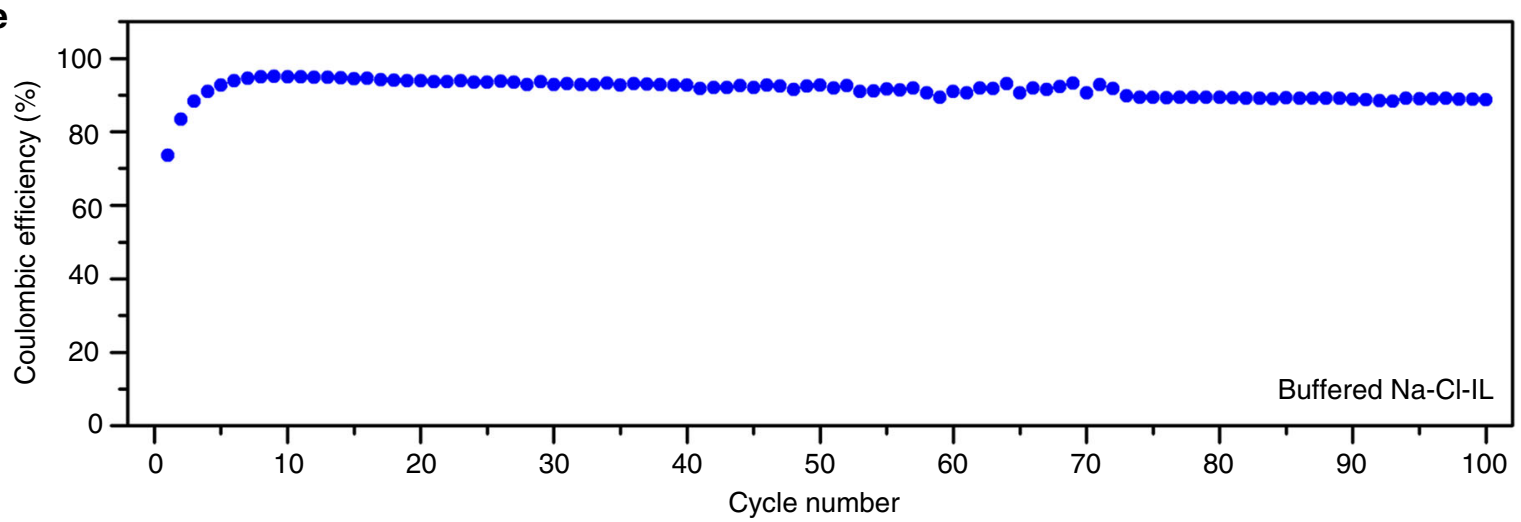

Fig. 2 Electrochemical properties of the buffered $\mathrm{Na}-\mathrm{Cl}-\mathrm{IL}$ electrolyte. a Linear sweep voltammetry profile of buffered $\mathrm{Na}-\mathrm{Cl}-\mathrm{IL}$ electrolyte. Working electrode, carbon fibre paper. Counter and reference electrode, $\mathrm{Na}$ foil. Scan rate, $2 \mathrm{mV} \mathrm{s}^{-1}$. b, c CV curves of Na/Pt cells using buffered $+\mathrm{EtAlCl}_{2}$ additive and buffered $\mathrm{Na}-\mathrm{Cl}-\mathrm{IL}$ electrolyte at a scan rate of $2 \mathrm{mV} \mathrm{s}^{-1}$, respectively. $\mathbf{d} \mathrm{Na}$ plating/stripping profiles of $\mathrm{Na} / \mathrm{Pt}$ cells using buffered $\mathrm{Na}-\mathrm{Cl}-\mathrm{IL}$ electrolyte at a current density of $0.5 \mathrm{~mA} \mathrm{~cm}{ }^{-2}$. e Na plating/stripping Coulombic efficiency of a Na/Pt cell using Buffered $\mathrm{Na}-\mathrm{Cl}-\mathrm{IL} \mathrm{electrolyte} \mathrm{at} 0.5 \mathrm{~mA} \mathrm{~cm}^{-2}$. The plating capacity in $(\mathbf{d}, \mathbf{e}): 0.25 \mathrm{mAh} \mathrm{cm}^{-2}$

cycling was performed for 100 cycles (Fig. 2e), which was the first-time multicycle $\mathrm{Na}$ redox was performed in buffered $\mathrm{AlCl}_{3} /$ [EMIm]Cl ILs. Without [EMIm]FSI additive in buffered $\mathrm{AlCl}_{3} /$ $[\mathrm{EMIm}] \mathrm{Cl}=1.5$ electrolyte, plating current was observed but without observable stripping capacity (Supplementary Fig. 1).

The morphology of the plated $\mathrm{Na}$ on $\mathrm{Cu}$ after five plating/ stripping cycles at a current density of 0.5 and $1.5 \mathrm{~mA} \mathrm{~cm}^{-2}$ was investigated by scanning electron microscopy (SEM), showing particle sizes ranging from 5 to $10 \mu \mathrm{m}$ without obvious dendritic morphology (Supplementary Fig. 2). The inner part of the $\mathrm{Na}$ particle was analyzed using focused ion beam (FIB) to expose cross-section of the interior (Supplementary Fig. 3). EDS element mapping of the cross-section revealed the existence of $\mathrm{Na}$ as the major element, together with $\mathrm{O}, \mathrm{Al}, \mathrm{F}$ and $\mathrm{C}$, and very little $\mathrm{Cl}$ was detected inside the particle, suggesting the distribution of $\mathrm{Cl}$ mainly on the surface of $\mathrm{Na}$ rather than inside (Supplementary Fig. 4). More detailed analysis of SEI on sodium negative electrodes are shown later in this paper.

$\mathrm{Na}$ metal cells based on Na-Cl-IL electrolyte. Next, we made a $\mathrm{Na}$ metal battery by pairing a $\mathrm{Na}$ negative electrode with a positive electrode formed by coating $\mathrm{Na}_{3} \mathrm{~V}_{2}\left(\mathrm{PO}_{4}\right)_{3} @$ reduced graphene oxide (NVP@rGO) particles on a carbon-fibre-paper 

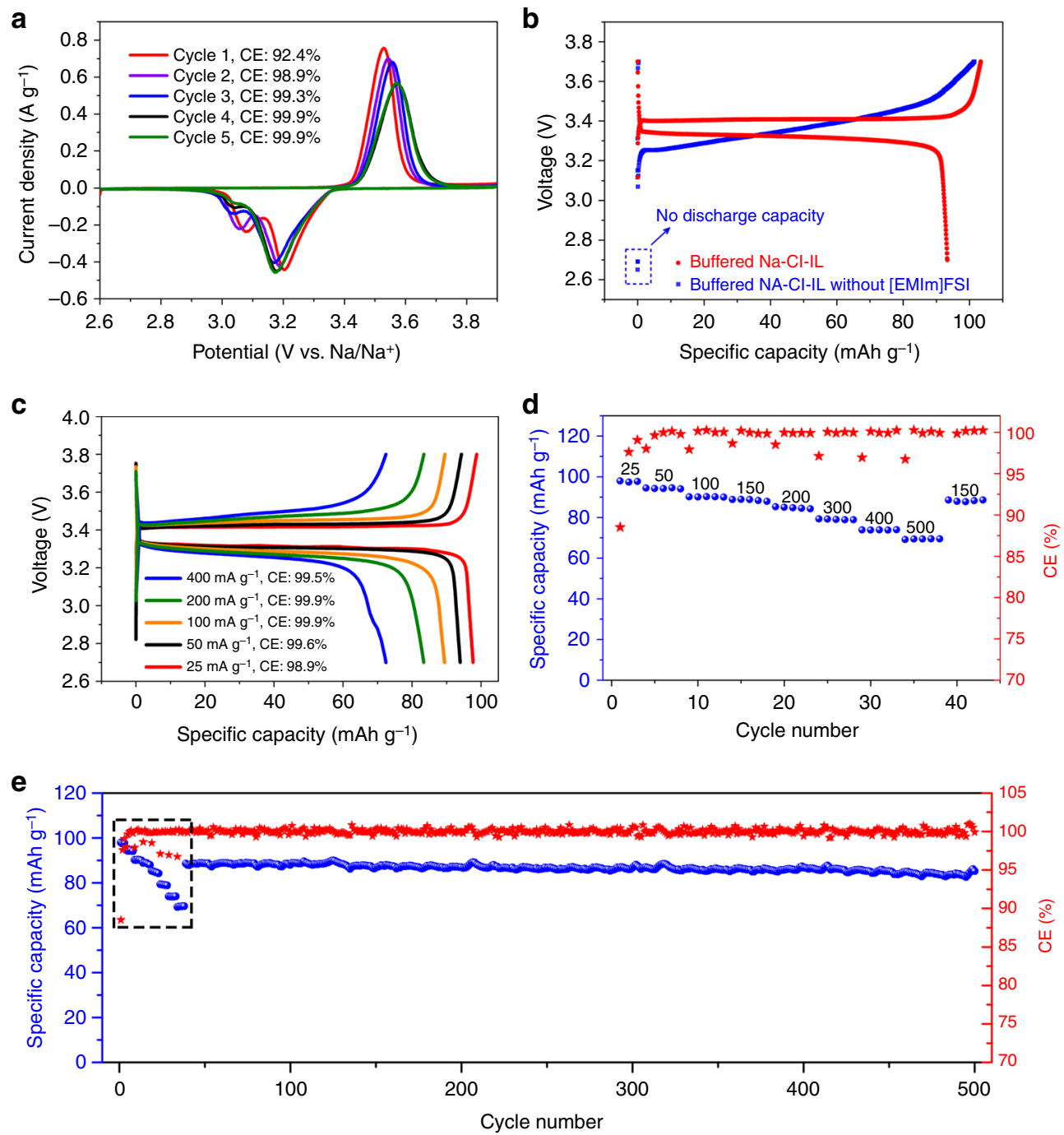

Fig. $3 \mathrm{Na} / \mathrm{NVP} / @ G O$ cell performances in buffered Na-Cl-IL electrolyte. a CV curves of a Na/NVP@rGO cell using buffered Na-Cl-IL electrolyte at a scan rate of $2 \mathrm{mV} \mathrm{s}^{-1}$. b Initial galvanostatic charge-discharge curves of a Na/NVP@rGO cell using buffered Na-Cl-IL electrolytes with and without [EMIm]FSI additive at $25 \mathrm{~mA} \mathrm{~g}^{-1}$. c Galvanostatic charge-discharge curves of a Na/NVP@rGO cell using buffered Na-Cl-IL electrolyte at varied current densities from 25 to $400 \mathrm{~mA} \mathrm{~g}^{-1}$. d, e Rate and cyclic stability of a Na/NVP@rGO cell using buffered Na-Cl-IL electrolyte. The boxed region of (e) corresponds to the rate performance of (d) at varied current densities from 20 to $500 \mathrm{~mA} \mathrm{~g}^{-1}$. After that, a current density of $150 \mathrm{~mA} \mathrm{~g}^{-1}$ was used for cycling

substrate (see Method). NVP was a widely explored positive electrode material for rapid and reversible $\mathrm{Na}$ ion insertion/deinsertion in its lattice, and the interconnected conducting network formed by rGO sheets further enhanced the charge transfer process $^{37,38}$. Powder X-ray diffraction (XRD) measurements showed a NASICON-type framework with $\mathrm{R} \overline{3} \mathrm{c}$ space group with high crystallinity of the synthesized NVP@rGO particles (Supplementary Fig. 5). SEM and transmission electron microscopy (TEM) showed NVP particles several hundred micrometers in size blended with rGO sheets (Supplementary Figs. 6 and 7). The lattice fringes with $d$-spacings of 0.44 and $0.34 \mathrm{~nm}$ were assigned to the (104) planes of rhombohedral NVP and (002) planes of multi-layered rGO respectively ${ }^{37}$. The rGO content of the NVP@rGO hybrid was around $1.1 \mathrm{wt} \%$ determined by thermogravimetric analysis (TGA, Supplementary Fig. 8).

Cyclic voltammetry of a Na/NVP@rGO cell with the optimized buffered Na-Cl-IL electrolyte (see supplementary Fig. 9 for electrolyte optimization) showed a pair of oxidation and reduction peaks corresponding to the redox reactions of $\mathrm{V}^{3}$ $+/ \mathrm{V}^{4+}$ couples, and the CE increased to $\sim 99.9 \%$ within four cycles and then stabilized (Fig. 3a). A mass loading of NVP@rGO $\sim 3.0 \mathrm{mg} \mathrm{cm}^{-2}$ was used unless specified otherwise. A chargedischarge plateau at $\sim 3.4 \mathrm{~V}$ was seen with a specific discharge capacity of $93.3 \mathrm{~mA} \mathrm{~g}^{-1}$ based on the mass of NVP@rGO at a rate of $25 \mathrm{~mA} \mathrm{~g}^{-1}$ (Fig. 3b). In striking contrast, the buffered $\mathrm{Na}$-Cl-IL electrolyte without [EMIm] FSI additive showed a negligible discharge capacity $\left(0.03 \mathrm{mAh} \mathrm{g}^{-1}\right)$ (Fig. 3b). The $\mathrm{Na} /$ NVP@rGO cell in buffered Na-Cl-IL electrolyte showed good rate capabilities at higher rates (Fig. 3c), with a specific discharge capacity of $\sim 70 \mathrm{mAh} \mathrm{g}^{-1}$ at $500 \mathrm{~mA} \mathrm{~g}^{-1}(\sim 4.3 \mathrm{C})$, which was $~$ $71 \%$ of the specific capacity at $25 \mathrm{~mA} \mathrm{~g}^{-1}$ (Fig. $3 \mathrm{~d}$ ). The $\mathrm{Na} /$ NVP@rGO cell could retain $\sim 96 \%$ of the initial capacity for over 460 cycles at $150 \mathrm{~mA} \mathrm{~g}^{-1}\left(\sim 0.4 \mathrm{~mA} \mathrm{~cm}{ }^{-2}\right)$ with a high average CE of 99.9 \% (Fig. 3e). This was the first time $>99 \%$ CE was achieved for $\mathrm{Na}$ metal battery in buffered chloroaluminate IL electrolytes. In comparison, a Na/NVP@rGO cell based on a conventional organic carbonate electrolyte, $1 \mathrm{M} \mathrm{NaClO}$ in ethylene carbonate/diethyl carbonate (EC/DEC, 1:1 by vol) with $5 \mathrm{wt} \%$ fluoroethylene carbonate (FEC) only retained $79 \%$ of the initial capacity after 450 cycles at $150 \mathrm{~mA} \mathrm{~g}^{-1}$ (Supplementary 

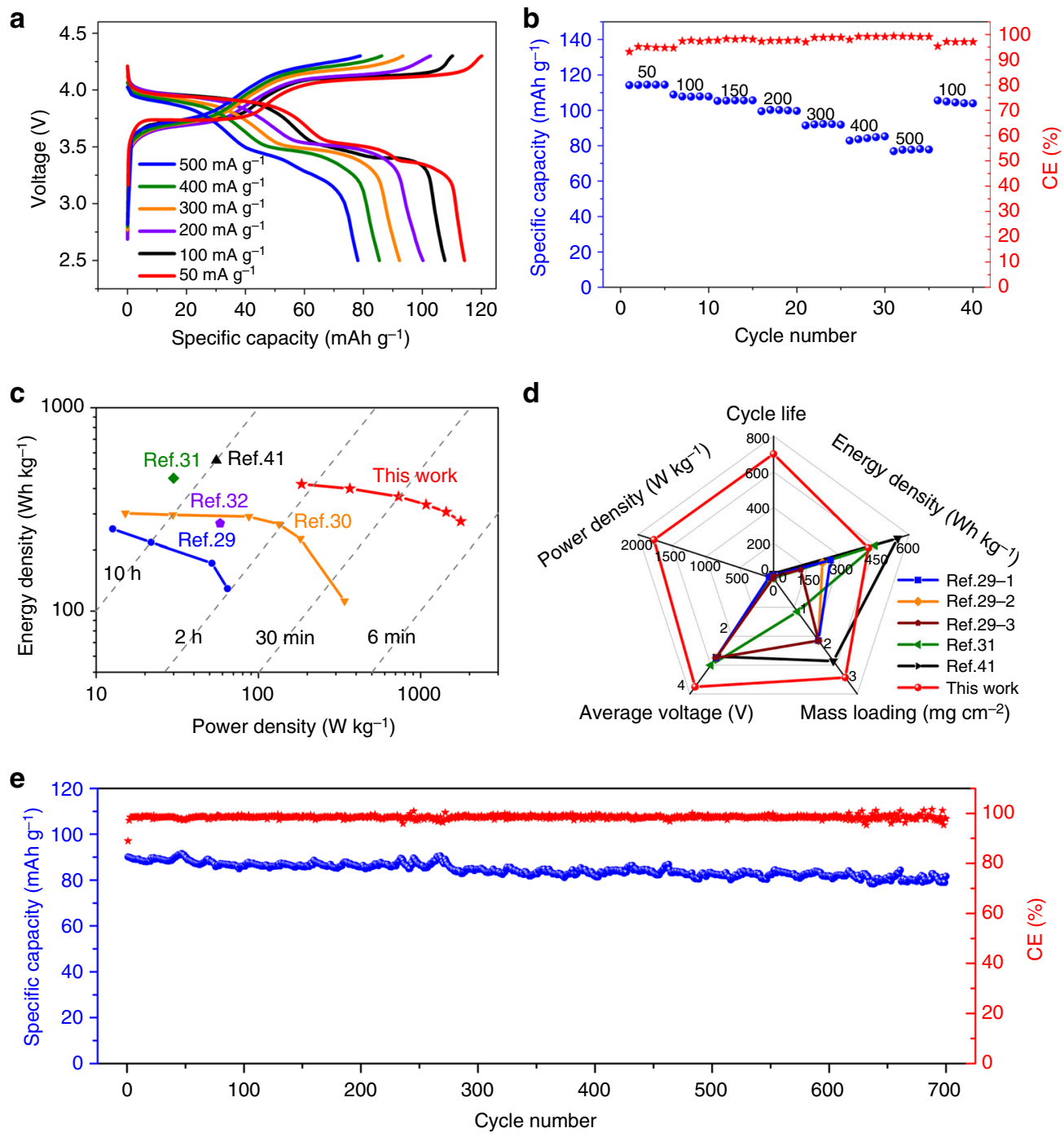

Fig. $4 \mathrm{Na}$ /NVPF@GO cell performances in buffered Na-Cl-IL electrolyte. a Galvanostatic charge-discharge curves of a Na/NVPF@rGO cell at varied current density from 50 to $500 \mathrm{~mA} \mathrm{~g}^{-1}$. b Capacity and Coulombic efficiency retention of a Na/NVPF@rGO cell when cycled at different current densities from 50 to $500 \mathrm{~mA} \mathrm{~g}^{-1}$. c, d Ragone and Radar plots of this work compared with other reported room-temperature Na batteries based on IL electrolytes, respectively 29-32,41. The specific capacity, energy and power density in this work and previous literatures were all calculated based on the mass of active materials on positive electrode. The cycle life in (d) is determined by the cycle number when the capacity dropped below $90 \%$ of the original capacity 29 . 1,2 and 3 represent three different IL electrolytes based on $1 \mathrm{M} \mathrm{NaBF}_{4}, \mathrm{NaClO}_{4}$ and $\mathrm{NaPF}_{6}$ salts, respectively. e Cyclic stability of a Na/NVPF@rGO cell using buffered $\mathrm{Na}-\mathrm{Cl}-\mathrm{IL}$ electrolyte at $300 \mathrm{~mA} \mathrm{~g}^{-1}$

Fig. 10), which is significantly lower than $\sim 96 \%$ based on buffered $\mathrm{Na}-\mathrm{Cl}-\mathrm{IL}$ electrolyte under the same condition. A similarly high average CE of $99.9 \%$ was demonstrated in organic electrolyte when the cell was stably cycled, but CE fluctuation was observed after 400 cycles (Supplementary Fig. 10). The $\mathrm{Na}$ / NVP@rGO cell based on buffered Na-Cl-IL electrolyte realized an approximate 100-cycle longer cycle life compared with that using conventional organic electrolyte. With an increased NVP@rGO mass loading of $8.0 \mathrm{mg} \mathrm{cm}^{-2}$, a specific discharge capacity of $\sim 92 \mathrm{mAh} \mathrm{g}^{-1}$ was delivered at $25 \mathrm{~mA} \mathrm{~g}^{-1}$ using buffered Na-Cl-IL electrolyte, corresponding to $94 \%$ of the capacity with $3.0 \mathrm{mg} \mathrm{cm}^{-2}$ loading (Supplementary Fig. 11). A slightly lower CE of $\sim 99.0 \%$ was demonstrated at the loading of $8.0 \mathrm{mg} \mathrm{cm}^{-2}$ compared with $\sim 99.9 \%$ at $3.0 \mathrm{mg} \mathrm{cm}^{-2}$.

With a stable voltage window up to $\sim 4.6 \mathrm{~V}$ (Fig. $2 \mathrm{a}$ ), the buffered $\mathrm{Na}-\mathrm{Cl}-\mathrm{IL}$ electrolyte was compatible with higher voltage positive electrodes such as $\mathrm{Na}_{3} \mathrm{~V}_{2}\left(\mathrm{PO}_{4}\right)_{2} \mathrm{~F}_{3} @ \mathrm{rGO}$ to afford $\mathrm{Na}$ metal battery cells with higher discharge voltage and energy density. We synthesized NVPF@rGO by a facile hydrothermal method, which was the first time NVPF@rGO hybrid was prepared via a one-step and low-temperature $\left(120^{\circ} \mathrm{C}\right)$ method without any freeze drying or annealing treatments ${ }^{39}$ (see Method). XRD patterns (Supplementary Fig. 12) indicated the prepared NVPF and NVPF@rGO mainly comprised of tetragonal $\mathrm{Na}_{3} \mathrm{~V}_{2}\left(\mathrm{PO}_{4}\right)_{2} \mathrm{~F}_{3}$ (ICDD PDF No. 01-089-8485) ${ }^{40}$ with an average size of $\sim 100 \mathrm{~nm}$. The NVPF particles were uniformly hybridized with rGO sheets, affording an interconnected conducting network to enhance electron transfer (Supplementary Fig. 13). The rGO content of the NVPF@rGO hybrid was around $4.4 \%$ verified by TGA (Supplementary Fig. 14). Two pairs of oxidation and reduction peaks $(3.75 \mathrm{~V} / 3.5 \mathrm{~V}$ and $4.12 \mathrm{~V} / 3.91 \mathrm{~V})$ were observed in the $\mathrm{CV}$ curves of the positive electrode, corresponding to redox reactions of $\mathrm{V}^{3+} / \mathrm{V}^{4+}$ and couples respectively (Supplementary Fig. 15). Compared to NVP@rGO with $\mathrm{V}^{3+} / \mathrm{V}^{4+}$ redox, the introduction of fluorine in NVPF@rGO allowed stable $\mathrm{V}^{4+} / \mathrm{V}^{5+}$ redox ${ }^{40}$, affording a higher charge/discharge plateau at $\sim 4 \mathrm{~V}$. The Na/NVPF@rGO cell based on buffered Na-Cl-IL electrolyte demonstrated good rate performances under 50 to $500 \mathrm{~mA} \mathrm{~g}^{-1}$ 
a Na Augar $\quad \mathrm{C}=\mathrm{O} \quad \mathrm{O}$ is $\quad$ b
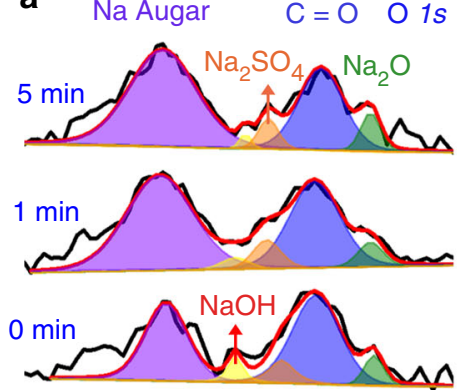

$\begin{array}{lllllll}540 & 538 & 536 & 534 & 532 & 530 & 528\end{array}$ b

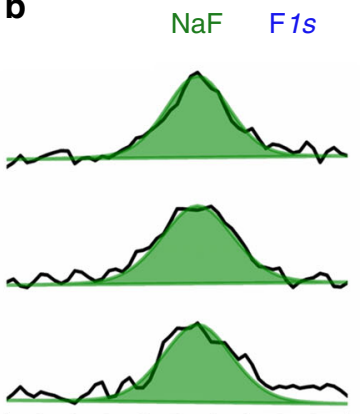

690688
C

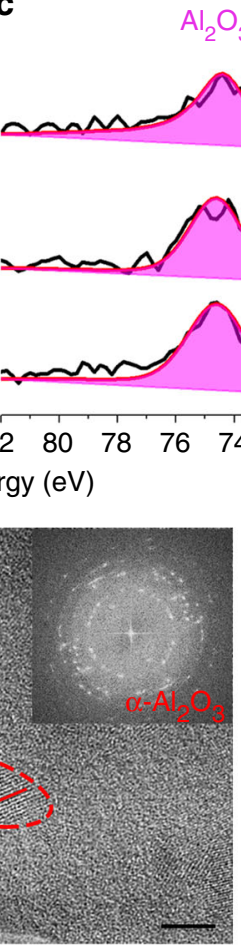

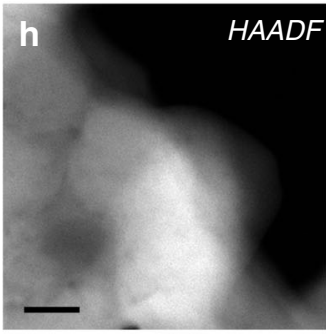
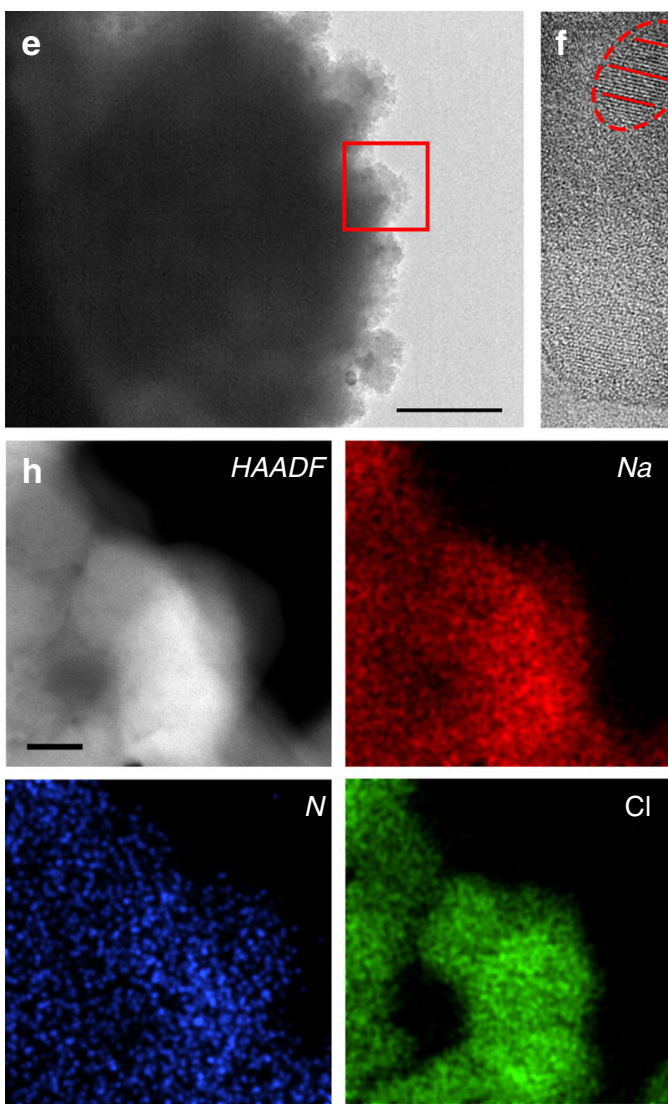

$\mathrm{Na}$
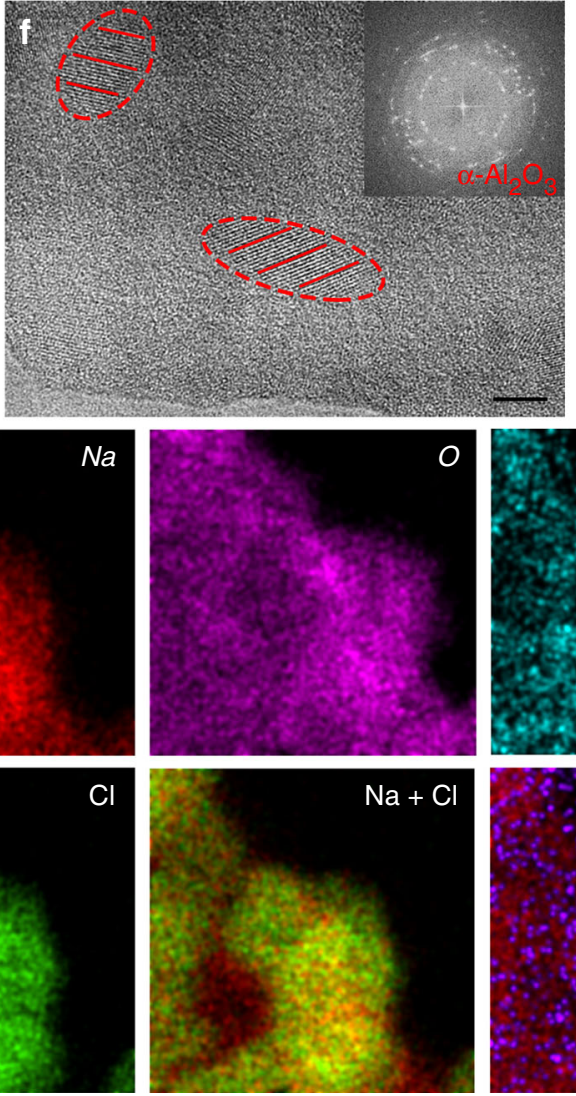
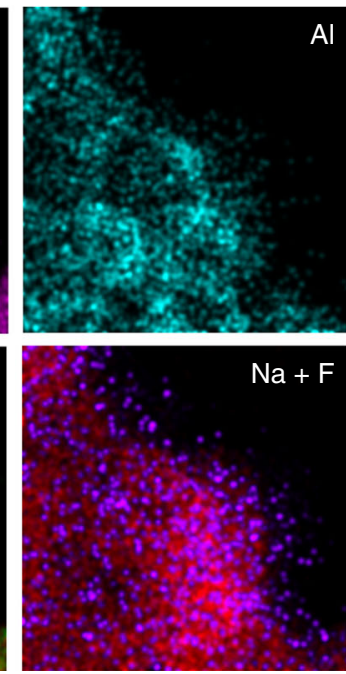

Al d
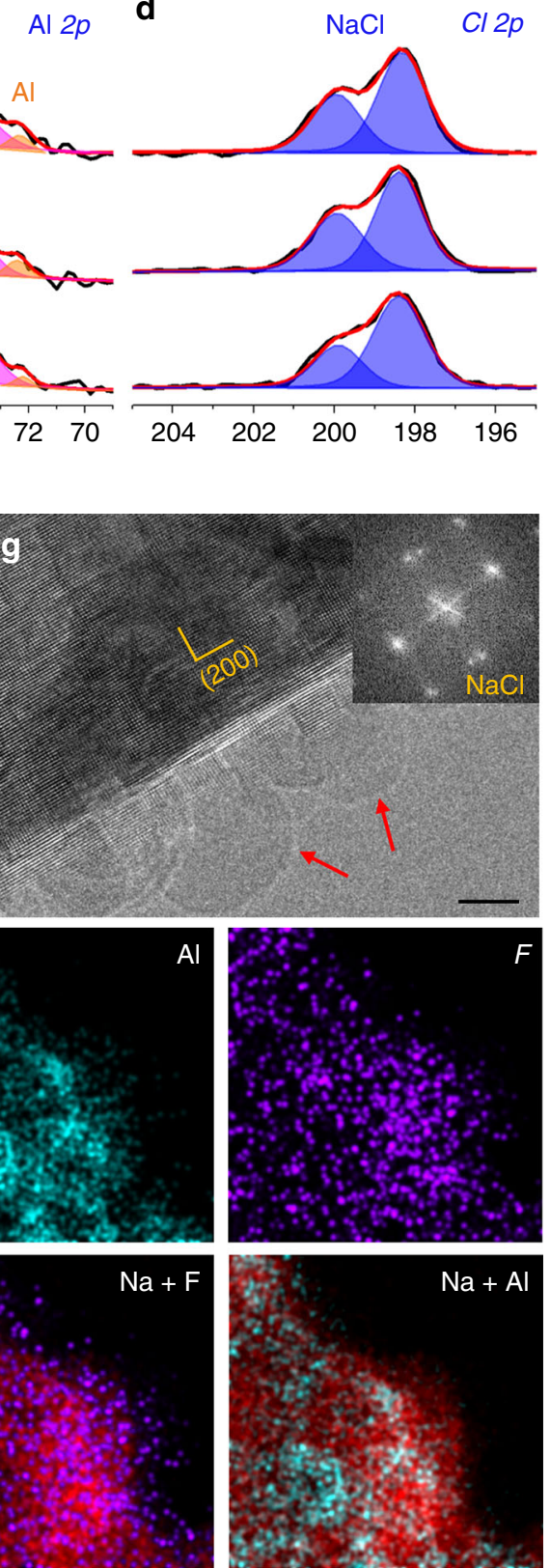

Fig. 5 Morphology and solid-electrolyte interphase (SEI) probing of the plated $\mathrm{Na}$ in buffered Na-Cl-IL electrolyte. a-d High-resolution XPS spectra for Na Auger and O1s (a), F 1s (b), Al 2p (c) and Cl 2p (d) of the Na negative electrode from a Na/NVP@rGO cell with NVP@rGO mass loading of 5.0 mg cm ${ }^{-2}$ at different depths, respectively. The cell was cycled at $100 \mathrm{~mA} \mathrm{~g}^{-1}\left(\sim 0.5 \mathrm{~mA} \mathrm{~cm}^{-2}\right)$ for 20 cycles and stopped at fully charged state prior to characterization. e Cryo-TEM image of Na-plated Cu grid at a current density of $0.1 \mathrm{~mA} \mathrm{~cm}-2$. Scale bar, $500 \mathrm{~nm}$. $\mathbf{f}, \mathbf{g}$ High-resolution Cryo-TEM images and diffraction patterns (inset) of $\mathrm{SEl}$ concerning $\mathrm{Al}_{2} \mathrm{O}_{3}$ and $\mathrm{NaCl}$. Scale bars in $(\mathbf{f}, \mathbf{g}), 5 \mathrm{~nm}$. $\mathbf{h}$ High-angle annular dark-field (HAADF) and the corresponding element mapping images for SEl composition probing using STEM. Scale bar, $100 \mathrm{~nm}$

$\left(0.16\right.$ to $\left.1.6 \mathrm{~mA} \mathrm{~cm}^{-2}\right)$ current densities and CEs from $95 \%$ to $99 \%$ (Fig. 4a, b). The maximal energy density was $\sim 420 \mathrm{Wh} \mathrm{kg}^{-1}$ based on the mass of NVPF@rGO. With an increase of NVPF mass loading from 3.0 to $8.0 \mathrm{mg} \mathrm{cm}^{-2}$, both the specific capacity and energy density were well retained, with an energy density of $\sim 394 \mathrm{Wh} \mathrm{kg}^{-1}$ at a mass loading of NVPF@rGO $\sim 8.0 \mathrm{mg} \mathrm{cm}^{-2}$ operated under a $50 \mathrm{~mA} \mathrm{~g}^{-1}\left(\sim 0.4 \mathrm{~mA} \mathrm{~cm}^{-2}\right)$ current (Supplementary Fig. 16). The NVPF@rGO positive electrode showed high energy density at various rates in the buffered $\mathrm{Na}-\mathrm{Cl}-\mathrm{IL}$ electrolyte (Fig. 4c), delivering an energy density of $276 \mathrm{Wh} \mathrm{kg}^{-1}$ in $\sim 10$ min discharging time, corresponding to a power density of $1766 \mathrm{~W} \mathrm{~kg} \mathrm{~kg}^{-1}$ based on the mass of NVPF@rGO at a current density of $500 \mathrm{~mA} \mathrm{~g}^{-1}\left(\sim 1.6 \mathrm{~mA} \mathrm{~cm}^{-2}\right)$. The superior rate performance over previous NVPF-based positive electrodes in IL electrolytes ${ }^{29-32,41}$ was attributed to the 2- to 20-fold higher ionic conductivity of the $\mathrm{Na}-\mathrm{Cl}-\mathrm{IL}$ electrolyte, and the novel NVPF@rGO hybrid that facilitated charge transfer ${ }^{42,43}$.

The Na/NVPF@rGO cell with a NVPF@rGO mass loading of $3.0 \mathrm{mg} \mathrm{cm}^{-2}$ showed excellent cycling stability in our IL electrolyte, retaining more than $90 \%$ of the initial specific capacity over 710 cycles at a current density of $300 \mathrm{~mA} \mathrm{~g}^{-1}$ $\left(\sim 0.81 \mathrm{~mA} \mathrm{~cm}^{-2}\right)$ with an average CE of $98.5 \%$ (Fig. $\left.4 \mathrm{e}\right)$. At a higher NVPF@rGO mass loading of $5.3 \mathrm{mg} \mathrm{cm}^{-2}$, a Na/ NVPF@rGO cell could retain 91\% of the initial specific capacity after 360 galvanostatic charge-discharge cycles at $150 \mathrm{~mA} \mathrm{~g}^{-1}$ $\left(\sim 0.7 \mathrm{~mA} \mathrm{~cm}^{-2}\right)$ with an average CE of $98.2 \%$ (Supplementary 
Fig. 17). The key performance parameters of the Na/NVPF@rGO cell in buffered $\mathrm{Na}-\mathrm{Cl}-\mathrm{IL}$ electrolyte, including energy/power density, cycle life, discharge voltage and mass loading outperformed previous cells based on room-temperature IL electrolytes $^{29,31,41}$ (Fig. 4d and Supplementary Table 1).

The $\mathrm{EtAlCl}_{2}$ additive was found important to enhance the cycling stability of $\mathrm{Na}$ batteries with $\mathrm{Na}-\mathrm{Cl}-\mathrm{IL}$ electrolyte, when comparing two Na/NVPF@rGO cells in IL electrolytes with and without $1 \mathrm{wt} \% \mathrm{EtAlCl}_{2}$ (Supplementary Fig. 18). The presence of $\mathrm{EtAlCl}_{2}$ additive improved cycle life by $\sim 500$ cycles at $300 \mathrm{~mA} \mathrm{~g}^{-1}$, which could be explained by the elimination of trace amounts of residual protons and free chloride ions in the electrolyte via equation (4).

Solid-electrolyte interphase chemistry of Na-Cl-IL electrolyte. It is well known that SEI plays a critical role in stabilizing the interface between alkali metal negative electrodes and electrolytes ${ }^{44-46}$. Due to the unusual composition of our IL electrolyte, the SEI chemistry could be different from that in conventional organic electrolytes. To this end, we first analyzed the elemental composition and depth profile by X-ray photoelectron spectroscopy (XPS) of a Na negative electrode from a Na/NVP@rGO cell with the mass loading of NVP@rGO $5.0 \mathrm{mg} \mathrm{cm}^{-2}$. The cell was cycled for 20 cycles at $100 \mathrm{~mA} \mathrm{~g}^{-1}\left(\sim 0.5 \mathrm{~mA} \mathrm{~cm}^{-2}\right)$ and stopped at a fully charged state ( $\mathrm{Na}$ plated on negative electrode). Surface XPS profile identified the presence of $\mathrm{Na}, \mathrm{O}, \mathrm{C}, \mathrm{Cl}, \mathrm{F}, \mathrm{Al}$ and $\mathrm{N}$ (Supplementary Fig. 19). XPS profiling by Ar sputtering showed pronounced $\mathrm{Na}$ Auger peak at $535.7 \mathrm{eV}$ at all sample depths (Fig. 5a). The $\mathrm{O} 1 \mathrm{~s}$ peaks at 531.2, 529.4, 532.2 and $533.6 \mathrm{eV}$ indicated the presence of $\mathrm{Na}_{2} \mathrm{CO}_{3}, \mathrm{Na}_{2} \mathrm{O}, \mathrm{Na}_{2} \mathrm{SO}_{4}$ and $\mathrm{NaOH}$, respectively (Fig. 5a). The presence of $\mathrm{NaOH}$ was only at the surface, as it was generated from the contamination by water when the sample was briefly exposed to air during transfer to XPS. Part of the $\mathrm{Na}_{2} \mathrm{CO}_{3}$ could also be from reaction with water and carbon dioxide in air and decreased in intensity after sputtering. In contrast, the intensity of $\mathrm{Na}_{2} \mathrm{O}$ and $\mathrm{Na}_{2} \mathrm{SO}_{4}$, formed by FSI anion and sodium metal showed no obvious decrease during sputtering, indicating their existence in SEI. As expected, the F $1 \mathrm{~s}$ peak at $\sim 685.5 \mathrm{eV}$ confirmed the presence of $\mathrm{NaF}$ as the major Fbased SEI (Fig. 5b). The FSI anions in [EMIm]FSI were responsible for F-based SEI via reactions with the highly reactive $\mathrm{Na}$ metal, consistent with previous literature ${ }^{47,48}$. The Al $2 p$ peaks at $74.5 \mathrm{eV}$ indicated the presence of $\mathrm{Al}_{2} \mathrm{O}_{3}$ as a major Al-based SEI component with a small portion of metallic $\mathrm{Al}$ observed (Fig. $5 \mathrm{c}$ ). The two pronounced peaks at $\sim 198.4$ and $199.8 \mathrm{eV}$ corresponded to $\mathrm{Cl} 2 p_{1 / 2}$ and $\mathrm{Cl} 2 p_{3 / 2}$ peaks, suggesting $\mathrm{NaCl}$ as another major SEI component (Fig. $5 \mathrm{~d}$ ). The weak $\mathrm{N} 1 s$ peak at $\sim 400 \mathrm{eV}$ indicated the presence of $\mathrm{N}$-based species generated from the decomposition of FSI anion (Supplementary Fig. 20), consistent with previous literature based on LiFSI-based organic electrolytes $^{49,50}$. Overall, a hybrid SEI formed on sodium metal comprised of $\mathrm{NaF}, \mathrm{Na}_{2} \mathrm{O}, \mathrm{Na}_{2} \mathrm{SO}_{4}, \mathrm{Al}_{2} \mathrm{O}_{3}, \mathrm{Al}$ and $\mathrm{NaCl}$ contributed to the reversible plating/stripping process of $\mathrm{Na}$ in buffered $\mathrm{Na}-\mathrm{Cl}-\mathrm{IL}$ electrolyte.

To gain a deeper insight into the Na plating process in buffered $\mathrm{Na}-\mathrm{Cl}-\mathrm{IL}$ electrolyte, cryogenic transmission electron microscope (Cryo-TEM) was used to probe the morphology and elemental composition of plated $\mathrm{Na}$ on $\mathrm{Cu}$ grids without exposing the sample to air (see "Methods" section). Cryo-TEM was demonstrated recently as a powerful tool in probing the morphological and component information of beam-sensitive battery materials such as Li metal ${ }^{51,52}$, but not yet used for investigating SEI on sodium thus far. We first investigated the initial Na plating on a $\mathrm{Cu}$ grid, which involved $\mathrm{Na}$ growth and SEI formation at the initial stage. The plated $\mathrm{Na}$ (without exposing to air) demonstrated a spherical morphology (Fig. 5e). High-resolution image showed some clusters in SEI with clear lattice fringes showing a $d$-spacing of $0.347 \mathrm{~nm}$ indexed to the (012) planes of a- $\mathrm{Al}_{2} \mathrm{O}_{3}$, which was also confirmed by diffraction pattern (Fig. $5 f$ ). In addition, the compact stacking of many nanocubes with an average size of $\sim 10 \mathrm{~nm}$ was observed on the edge of SEI, with lattice fringes at a $d$-spacing of $0.284 \mathrm{~nm}$ indexed to (200) planes of $\mathrm{NaCl}$ and corroborated by diffraction pattern (Fig. $5 \mathrm{~g}$ ).

Element mapping analysis on these regions was performed using scanning transmission electron microscopy (STEM), indicating the presence of $\mathrm{Na}, \mathrm{O}, \mathrm{Cl}, \mathrm{Al}, \mathrm{F}$ and $\mathrm{N}$ that was in accordance with the XPS results, confirming the hybrid SEI composition of this novel IL electrolyte (Fig. 5h). The overlapped $\mathrm{Na}$ and $\mathrm{Cl}$ mapping indicated the presence of $\mathrm{NaCl}$, which was consistent with the stacking cubes and diffraction pattern of $\mathrm{NaCl}$ detected in Cryo-TEM (Fig. 5f). The F mapping mainly distributed in the region near the surface, and showed a good overlap with $\mathrm{Na}$ mapping, which was in accordance with the XPS results that indicated the presence of $\mathrm{NaF}$ layer. The merged $\mathrm{Na}$ and $\mathrm{Al}$ mapping showed the aggregation of $\mathrm{Al}$ with the formation of some Al clusters, rather than distribute uniformly with $\mathrm{Na}$ in the SEI matrix (Fig. 5h). It can be explained by the fact that $\mathrm{Al}$ and $\mathrm{Na}$ cannot form an alloy; thus, $\mathrm{Al}$ might prefer to plate on $\mathrm{Al}$ rather than $\mathrm{Na}$, which could account for the interconnected structure of $\mathrm{Al}$ observed in the mapping image.

\section{Discussion}

Compared with previous IL electrolytes for $\mathrm{Na}$ cells, the $\mathrm{Na}-\mathrm{Cl}-\mathrm{IL}$ electrolyte system is interesting in several ways. First, the high ionic conductivity $\left(\sim 9.2 \mathrm{mS} \mathrm{cm}-1\right.$ at $\left.25^{\circ} \mathrm{C}\right)$ outperforms previously reported IL electrolytes based on bulky cations (e.g., benzyldimethylethylammonium and $N$-butyl- $N$-methylpyrrolidinium) and anions (e.g., $\mathrm{FSI}^{-}$and $\mathrm{TFSI}^{-}$), allowing for both high-energy density and rate capability/power density of the $\mathrm{Na}$ metal cells (Supplementary table 1$)^{29-32}$. The EMIm cation is unique among other cations since it provides delocalized positive charge around the imidazolium ring, effectively increasing the cation-anion distance and affording lower viscosities than ILs with other cations, owing to reduced Coulomb (electrostatic) interactions between ion pairs ${ }^{53}$. Second, the SEI components are unique with the inclusion of $\mathrm{AlO}_{\mathrm{x}}$ and $\mathrm{NaCl}$ due to $\mathrm{Na}$ reaction/passivation by chloroaluminate species, which facilitates the stabilization of $\mathrm{Na}$ plating/stripping cycling. This led to a cycle life of over 700 cycles, the longest among all the reported IL-based Na cells ${ }^{29-31,41}$ (Fig. 4d).

We found that although FSI anions was indispensable for a stable SEI in our system, FSI alone was not sufficient for long cycle life of $\mathrm{Na}$ negative electrode. This was based on inferior cycling stability of Na/NVP@rGO cell in a non-chloroaluminate based electrolyte $1 \mathrm{M}$ NaFSI in [EMIm]FSI IL electrolyte, displaying low and fluctuating CEs of only $\sim 90 \%$, despite the fact that it had a much higher FSI anion concentration of $\sim 6 \mathrm{M}$ compared with only $\sim 0.2 \mathrm{M}$ in the buffered $\mathrm{Na}-\mathrm{Cl}-\mathrm{IL}$ electrolyte (Supplementary Fig. 21). Similarly, the Na/NVP@rGO cell using $\mathrm{NaFSI}$ in N-propyl-N-methylpyrrolidinium bis(fluorosufonyl) imide IL electrolyte (molar ratio of 2:8) showed fluctuating CEs after $\sim 65$ cycles when cycling at $150 \mathrm{~mA} \mathrm{~g}^{-1}$ (Supplementary Fig. 22). In addition, an inferior rate performance was demonstrated using NaFSI/N-propyl-N-methylpyrrolidinium bis(fluorosufonyl)imide IL electrolyte compared with that based on buffered Na-Cl-IL electrolyte (Supplementary Fig. 23).

Another important aspect was that previous IL electrolytes with highly concentrated F-based species (e.g., over $5 \mathrm{M}$ of FSI anion concentration in NaFSI-[ $N$-propyl- $N$-methylpyrrolidinium]FSI electrolyte with a molar ratio of $2: 8)^{32}$ were much higher in cost than conventional organic electrolytes due to expensive FSI species. A 
much lower FSI concentration of only $\sim 0.2 \mathrm{M}$ was needed for the buffered $\mathrm{Na}-\mathrm{Cl}-\mathrm{IL}$ electrolyte, and at the same time reaching better cell performances (power density, CE, cycle life and discharge voltage etc.) than previous room temperature IL electrolytes (Supplementary Table 1). The buffered Na-Cl-IL electrolyte could be a promising candidate for affordable, high-safety energy storage towards realworld applications.

In conclusion, we develop a non-flammable and highly conductive ionic liquid electrolyte for high-energy/high-voltage $\mathrm{Na}$ metal batteries. The ionic liquid electrolyte is comprised of $\mathrm{AlCl}_{3}$, $\mathrm{NaCl}$ and $[\mathrm{EMIm}] \mathrm{Cl}$ and allows reversible $\mathrm{Na}$ plating/stripping upon addition of two additives, i.e., ethylaluminum dichloride and 1-ethyl-3-methylimidazolium bis(fluorosulfonyl)imide. The $\mathrm{Na}$ metal cells with NVP and NVPF positive electrodes achieve high CE up to $99.9 \%$, and high energy and power density of 420 $\mathrm{Wh} \mathrm{kg}-1$ and $1766 \mathrm{~W} \mathrm{~kg}^{-1}$, respectively. Over $90 \%$ of the original capacity can be retained after over 700 galvanostatic chargedischarge cycles. The solid-electrolyte interphase (SEI) probed by XPS and Cryo-TEM shows that the major components included $\mathrm{NaCl}, \mathrm{Al}_{2} \mathrm{O}_{3}$ and $\mathrm{NaF}$. The non-flammable and highly conductive IL electrolyte can serve as a promising candidate for sodium batteries with high safety and high performance, and can be potentially extended to a broad range of rechargeable battery systems such as $\mathrm{Li}$ and $\mathrm{K}$ batteries.

\section{Methods}

Preparation of IL electrolytes. IL electrolytes were prepared in an Ar-filled glove box with water and oxygen content below $2 \mathrm{ppm}$. [EMIm] $\mathrm{Al}_{x} \mathrm{Cl}_{y}$ IL was first made by mixing 1-ethyl-3-methylimidazolium chloride ([EMIm] Cl) and anhydrous $\mathrm{AlCl}_{3}$ ( $\geq 99.0 \%$, Fluka). [EMIm] Cl was dried at $80^{\circ} \mathrm{C}$ under vacuum for $24 \mathrm{~h}$ to remove residual water. For a certain molar ratio, e.g., 1.5 of $\mathrm{AlCl}_{3} /[\mathrm{EMIm}] \mathrm{Cl}, 1.78 \mathrm{~g}$ of [EMIm] Cl and $2.4 \mathrm{~g}$ of $\mathrm{AlCl}_{3}$ were weighed in two glass vials, respectively. A small portion of $\mathrm{AlCl}_{3}$ was then slowly added into [EMIm] Cl to avoid dramatic heat generation during the mixing. This process was repeated until all the $\mathrm{AlCl}_{3}$ were introduced, and the mixture was stirred until all the solid was dissolved, followed by adding around $0.3 \mathrm{~g}$ of aluminum foil for purification. $1.8 \mathrm{~g}$ of the obtained light-yellow, clear liquid was kept at $70{ }^{\circ} \mathrm{C}$ for $1 \mathrm{~h}$ under vacuum for removal of water, followed by adding $0.172 \mathrm{~g} \mathrm{NaCl}$ (99.999\%, Sigma-Aldrich) and allowed to stir for $24 \mathrm{~h}$. The supernatant was collected, and stirred with $1 \mathrm{wt} \%$ $\mathrm{EtAlCl}_{2}$ (Sigma-Aldrich) for $1 \mathrm{~h}$. The mixture was further added with $4 \mathrm{wt} \%$ [EMIm]FSI (dried at $70^{\circ} \mathrm{C}$ under vacuum for $12 \mathrm{~h}$ before use) and allowed to stir for $6 \mathrm{~h}$ to obtain the buffered $+\mathrm{EtAlCl}_{2} /[\mathrm{EMIm}] \mathrm{FSI}$ additive electrolyte. To avoid water absorption of the prepared IL electrolyte, all the agents were stored inside tightly closed and sealed bottles, and placed in Ar-filled glove box. [EMIm] $\mathrm{Cl}$ and $\mathrm{NaCl}$ were dried via heating under vacuum before use. [EMIm]FSI and $\mathrm{N}$-propyl$\mathrm{N}$-methylpyrrolidinium bis(fluorosufonyl)imide were dried under vacuum at $70^{\circ} \mathrm{C}$ for $12 \mathrm{~h}$ before dissolving NaFSI salt. $1 \mathrm{M} \mathrm{NaClO}_{4}$ in $\mathrm{EC} / \mathrm{DEC}$ ( $1: 1 \mathrm{by} \mathrm{vol}$ ) with $5 \mathrm{wt}$ $\%$ FEC was prepared as conventional organic electrolyte for comparison.

Preparation of NVP@rGO and NVPF@rGO. Graphene oxide (GO) was synthesized via a modified Hummer's method with more details described in Supplementary Information ${ }^{54}$. To prepare NVP@rGO, $0.69 \mathrm{~g}$ of $\mathrm{NH}_{4} \mathrm{H}_{2} \mathrm{PO}_{4}, 0.318 \mathrm{~g}$ of $\mathrm{Na}_{2} \mathrm{CO}_{3}$ and $0.364 \mathrm{~g}$ of $\mathrm{V}_{2} \mathrm{O}_{5}$ were dispersed in deionized water, followed by adding $0.72 \mathrm{~g}$ of oxalic acid ( $\geq 99.0 \%$, Sigma-Aldrich) at $70^{\circ} \mathrm{C}$. The mixture was added with $7.3 \mathrm{~mL} \mathrm{GO}$ aqueous dispersion $\left(11 \mathrm{mg} \mathrm{mL}^{-1}\right)$ under vigorous stirring, and then freeze-dried to obtain the solid NVP@GO precursor. The precursor was grounded using an agate mortar, followed by sintering at $850^{\circ} \mathrm{C}$ with a heating rate of $2^{\circ} \mathrm{C} \mathrm{min}-1$ in Ar to obtain the NVP@rGO powder. NVPF@rGO was prepared via a one-step hydrothermal method. Briefly, $0.536 \mathrm{~g}$ of NaF, $3.51 \mathrm{~g}$ of $\mathrm{NaH}_{2} \mathrm{PO}_{4} \cdot 2 \mathrm{H}_{2} \mathrm{O}$ and $1.763 \mathrm{~g}$ of $\mathrm{VOSO}_{4} \cdot x \mathrm{H}_{2} \mathrm{O}$ (degree of hydration 3-5, SigmaAldrich) were dissolved in $30 \mathrm{~mL}$ deionized water, followed by mixing with $7.8 \mathrm{~mL}$ of GO aqueous dispersion (11 mg mL $\mathrm{m}^{-1}$ ) for $1 \mathrm{~h}$ to obtain a uniform dispersion. The mixture was immediately transferred into a $45 \mathrm{~mL}$ Teflon-lined stainless steel autoclave and kept at $120^{\circ} \mathrm{C}$ for $10 \mathrm{~h}$. The resulted precipitates were centrifuged at $4,000 \mathrm{rpm}$ using deionized water for 5 times, and the obtained solid was dried at 80 ${ }^{\circ} \mathrm{C}$ for $10 \mathrm{~h}$ in a vacuum oven to obtain the NVPF@rGO powder. For bare NVPF, no GO was added with all the other procedures remained the same.

Electrochemical measurements. All the electrochemical measurements were conducted at room temperature $\left(22^{\circ} \mathrm{C}\right)$ unless otherwise specified. To prepare slurries, 70 wt\% NVP@rGO or NVPF@rGO powder was mixed with 20 wt $\%$ conductive carbon black (Super C65, TIMICAL) and $10 \mathrm{wt} \%$ polyvinylidene fluoride (PVDF, $\mathrm{M}_{\mathrm{w}}$

180,000, Sigma-Aldrich) in N-methyl-2-pyrrolidone (NMP, $99.5 \%$, Sigma-Aldrich). The mixture was stirred for $10 \mathrm{~h}$ until a uniform and viscose slurry was obtained, which was coated on a Mitsubishi carbon fibre paper (M30 type, $30 \mathrm{~g} \mathrm{~m}^{-2}$ ). The electrodes were baked in a $120^{\circ} \mathrm{C}$ vacuum oven for $2 \mathrm{~h}$ for removal of the residual NMP. The electrochemical performances were measured in pouch-type cells. Briefly, carbon tap (Ted Pella) was used to paste the positive electrode (Cu or Pt foil, NVP@rGO or NVPF@rGO electrodes) and negative electrode of $\mathrm{Na}$ metal foil onto an aluminum laminated pouch. The Na foil was prepared by rinsing a Na cube $(99.9 \%$, SigmaAldrich) in anhydrous dimethyl carbonate ( $\geq 99.0 \%$, Sigma-Aldrich) for removal of the mineral oil on surface, cutting off the surface oxidation with blades, and pressing a fresh piece into a thin foil. Two nickel tabs (EQ-PLiB-NTA3, MTI) and a piece of glass fibre filter paper (GF/A, Whanman) were served as the current collector and separator, respectively. The obtained pouch was heated in an $80^{\circ} \mathrm{C}$ vacuum oven for $8 \mathrm{~h}$, and then transferred into an argon-filled glove box with water and oxygen content below $2 \mathrm{ppm}$ to fill in the electrolyte $(200 \mathrm{uL}$ for each cell). The pouch was heat-sealed in the glove box before transferring out for further electrochemical measurement. Cyclic voltammetry was performed on a CHI760E electrochemical work station. The chargedischarge performances of the cells were measured with a Neware battery testing system (CT-4008-5V50mA-164-U). All the cells were allowed to age for $6 \mathrm{~h}$ before chargedischarge measurement. The specific capacity, energy and power density were calculated based on the total mass of NVP@rGO and NVPF@rGO.

Characterization. For Raman spectra, IL electrolytes were injected and sealed into transparent plastic pouches in an Ar-filled glove box. The spectra were acquired $\left(250-500 \mathrm{~cm}^{-1}\right)$ using an $\mathrm{Ar}^{+}$laser $(532 \mathrm{~nm})$ with $0.8 \mathrm{~cm}^{-1}$ resolution. The conductivity measurement was performed on a conductivity meter (FiveEasy Plus, Mettler Toledo). Prior to characterization, the electrodes were rinsed with anhydrous dimethyl carbonate for 6 times, and dried under vacuum at room temperature. They were further sealed in Ar-filled pouches and quickly transferred into the vacuum chamber to avoid too much exposure to air. The $\mathrm{Na}$ ion concentration of the buffered Na-Cl-IL electrolyte was measured using a Thermo Scientific ICAP 6300 Duo View Spectrometer. SEM images were acquired from a Hitachi/S- 4800 SEM operated at $15 \mathrm{kV}$, and EDS analysis was performed on a Horiba/Ex-450 EDS spectroscopy. FIB-SEM was performed on a dual-beam field-emitting focused ion beam microscope (VERSA 3D DualBeam) with an accelerating voltage of $20 \mathrm{kV}$. TEM image of NVP@rGO was obtained with a JEOL JEM-2100F operated at 200 $\mathrm{kV}$. XRD pattern was measured with a Bruker D8 Advance powder X-ray diffractometer with $\mathrm{Cu} \mathrm{Ka}$ radiation. TGA measurement was performed on a PerkinElmer/Diamond TG/DTA thermal analyser at a heating rate of $5^{\circ} \mathrm{C} \min ^{-1}$ in air for NVP@rGO and NVPF@rGO, and in nitrogen for IL and organic electrolyte respectively. The temperature range used for determining rGO percentage was $180-460^{\circ} \mathrm{C}$, and the weight loss below $180^{\circ} \mathrm{C}$ was due to water removal that is also used to determine the water content of products synthesized in aqueous solution ${ }^{55}$. XPS spectra were collected on a PHI 5000 VersaProbe Scanning XPS Microprobe. All the binding energy values were calibrated with $\mathrm{C} 1 \mathrm{~s}$ peak $(284.6 \mathrm{eV})$. Depth profile was conducted using Ar ion sputtering at $1 \mathrm{kV}$ and $0.5 \mu \mathrm{A}$ over a $2 \times 2 \mathrm{~mm}$ area, corresponding to a $\mathrm{SiO}_{2}$ sputter rate of $2 \mathrm{~nm} \mathrm{~min}{ }^{-1}$. Glass fibre separators soaked with electrolyte were used to test the flammability of the electrolyte. CryoTEM was performed on an FEI Titan Krios cryogenic transmission electron microscope operated at $300 \mathrm{kV}$. Na was plated on a Cu TEM grid in a 2032 type coin cell at a current density of $\sim 0.2 \mathrm{~mA} \mathrm{~cm}^{-2}$ for $30 \mathrm{~min}$, using $150 \mathrm{uL} \mathrm{Na}-\mathrm{Cl}-\mathrm{IL}$ and one glass fibre as electrolyte and separator, respectively. The coin cell was disassembled in an Ar-filled glove box, followed by removing the residual electrolyte on Na-plated Cu TEM grid using anhydrous DMC and drying it under vacuum. The TEM grid was then carefully mounted onto a TEM cryo-holder and transferred into the chamber of Cryo-TEM without exposing to air. Similar processes were performed for element mapping using a FEI Titan Themis 60-300 transmission electron microscope equipped with a cooling sample holder.

\section{Data availability}

The data that support the plots within this paper and other findings of this study are available from the corresponding author upon reasonable request.

Received: 21 March 2019 Accepted: 20 June 2019

Published online: 24 July 2019

\section{References}

1. Armand, M. \& Tarascon, J. M. Building better batteries. Nature 451, 652 (2008).

2. Cano, Z. P. et al. Batteries and fuel cells for emerging electric vehicle markets. Nat. Energy 3, 279-289 (2018).

3. Dunn, B., Kamath, H. \& Tarascon, J.-M. Electrical energy storage for the grid: a battery of choices. Science 334, 928-935 (2011).

4. $\mathrm{Xu}, \mathrm{X}$. et al. A room-temperature sodium-sulfur battery with high capacity and stable cycling performance. Nat. Commun. 9, 3870 (2018).

5. Zhou, D. et al. A stable quasi-solid-state sodium-sulfur battery. Angew. Chem. Int. Ed. 57, 10168-10172 (2018) 
6. Xiong, P. et al. Two-dimensional unilamellar cation-deficient metal oxide nanosheet superlattices for high-rate sodium ion energy storage. ACS Nano 12, 12337-12346 (2018).

7. Roth, E. P. \& Orendorff, C. J. How electrolytes influence battery safety. Electrochem. Soc. Interface 21, 45-49 (2012).

8. Finegan, D. P. et al. In-operando high-speed tomography of lithium-ion batteries during thermal runaway. Nat. Commun. 6, 6924 (2015).

9. Chen, Z. et al. Fast and reversible thermoresponsive polymer switching materials for safer batteries. Nat. Energy 1, 15009 (2016).

10. Liu, K. et al. Electrospun core-shell microfiber separator with thermaltriggered flame-retardant properties for lithium-ion batteries. Sci. Adv. 3, e1601978 (2017)

11. Li, S. L. et al. A poly(3-decyl thiophene)-modified separator with self-actuating overcharge protection mechanism for $\mathrm{LiFePO}_{4}$-based lithium ion battery. J. Power Sources 196, 7021-7024 (2011).

12. Streipert, B. et al. Evaluation of allylboronic acid pinacol ester as effective shutdown overcharge additive for lithium ion cells. J. Electrochem. Soc. 164 A168-A172 (2017)

13. Fan, X. et al. Non-flammable electrolyte enables Li-metal batteries with aggressive cathode chemistries. Nat. Nanotechnol. 13, 715-722 (2018).

14. Zeng, Z. et al. Non-flammable electrolytes with high salt-to-solvent ratios for Li-ion and Li-metal batteries. Nat. Energy 3, 674-681 (2018).

15. Wang, J. et al. Fire-extinguishing organic electrolytes for safe batteries. Nat Energy 3, 22-29 (2018).

16. Yang, Q. et al. Ionic liquids and derived materials for lithium and sodium batteries. Chem. Soc. Rev. 47, 2020-2064 (2018).

17. Webber, A. \& Blomgren, G. E. in Advances in Lithium-Ion Batteries (eds Walter, A, van Schalkwijk \& Scrosati, B.) Ch. 6 (Springer, US, 2002).

18. Giffin, G. A. Ionic liquid-based electrolytes for "beyond lithium" battery technologies. J. Mater. Chem. A 4, 13378-13389 (2016).

19. Pickup, P. G. \& Osteryoung, R. A. Charging and discharging rate studies of polypyrrole films in $\mathrm{AlCl}_{3}$ : 1-methyl-(3-ethyl)-imidazolium chloride molten salts and in $\mathrm{CH}_{3} \mathrm{CN}$. J. Electroanal. Chem. Interfacial Electrochem. 195, 271-288 (1985).

20. Lin, M.-C. et al. An ultrafast rechargeable aluminium-ion battery. Nature 520, 324 (2015)

21. Jayaprakash, N., Das, S. K. \& Archer, L. A. The rechargeable aluminum-ion battery. Chem. Commun. 47, 12610-12612 (2011).

22. Melton, T. J., Joyce, J., Maloy, J. T., Boon, J. A. \& Wilkes, J. S. Electrochemical studies of sodium chloride as a lewis buffer for room temperature chloroaluminate molten salts. J. Electrochem. Soc. 137, 3865-3869 (1990).

23. Gray, G. E., Kohl, P. A. \& Winnick, J. Stability of sodium electrodeposited from a room temperature chloroaluminate molten salt. J. Electrochem. Soc. 142, 3636-3642 (1995).

24. Riechel, T. L. \& Wilkes, J. S. Reversible plating and stripping of sodium at inert electrodes in room temperature chloroaluminate molten salts. J. Electrochem. Soc. 139, 977-981 (1992).

25. Riechel, T. L., Miedler, M. J. \& Schumacher, E. R. Studies of the cathodic limit of proton-modified room temperature chloroaluminate molten salt electrolytes. Electrochem. Soc. Proc. Vol. 94-13, 491-497 (1994).

26. Piersma, B. J., Ryan, D. M., Schumacher, E. R. \& Riechel, T. L. Electrodeposition and stripping of lithium and sodium on inert electrodes in room temperature chloroaluminate molten salts. J. Electrochem. Soc. 143, 908-913 (1996).

27. Fuller, J., Osteryoung, R. A. \& Carlin, R. T. Rechargeable lithium and sodium anodes in chloroaluminate molten salts containing thionyl chloride. $J$. Electrochem. Soc. 142, 3632-3636 (1995).

28. Zawodzinski, T. A., Carlin, R. T. \& Osteryoung, R. A. Removal of protons from ambient-temperature chloroaluminate ionic liquids. Anal. Chem. 59, 2639-2640 (1987).

29. Wongittharom, N., Wang, C.-H., Wang, Y.-C., Yang, C.-H. \& Chang, J.-K. Ionic liquid electrolytes with various sodium solutes for rechargeable na/ nafepo4 batteries operated at elevated temperatures. ACS Appl. Mater. Interfaces 6, 17564-17570 (2014)

30. Wang, C.-H. et al. Rechargeable $\mathrm{Na} / \mathrm{Na}_{0.44} \mathrm{MnO}_{2}$ cells with ionic liquid electrolytes containing various sodium solutes. J. Power Sources 274, 1016-1023 (2015).

31. Hasa, I., Passerini, S. \& Hassoun, J. Characteristics of an ionic liquid electrolyte for sodium-ion batteries. J. Power Sources 303, 203-207 (2016).

32. Ding, C. et al. NaFSA-C1C3pyrFSA ionic liquids for sodium secondary battery operating over a wide temperature range. J. Power Sources 238, 296-300 (2013).

33. Ponrouch, A., Marchante, E., Courty, M., Tarascon, J.-M. \& Palacín, M. R. In search of an optimized electrolyte for Na-ion batteries. Energy Environ. Sci. 5, 8572-8583 (2012).

34. Doyle, K. P., Lang, C. M., Kim, K. \& Kohl, P. A. Dentrite-free electrochemical deposition of Li-Na alloys from an ionic liquid electrolyte. J. Electrochem. Soc. 153, A1353-A1357 (2006).
35. Matsumoto, K., Taniki, R., Nohira, T. \& Hagiwara, R. Inorganic-organic hybrid ionic liquid electrolytes for Na secondary batteries. J. Electrochem. Soc. 162, A1409-A1414 (2015).

36. Mohd Noor, S. A., Howlett, P. C., MacFarlane, D. R. \& Forsyth, M. Properties of sodium-based ionic liquid electrolytes for sodium secondary battery applications. Electrochim. Acta 114, 766-771 (2013).

37. $\mathrm{Xu}$, Y. et al. Layer-by-Layer $\mathrm{Na}_{3} \mathrm{~V}_{2}\left(\mathrm{PO}_{4}\right)_{3}$ embedded in reduced graphene oxide as superior rate and ultralong-life sodium-ion battery cathode. $A d v$. Energy Mater. 6, 1600389 (2016).

38. Zhang, J. et al. Graphene-scaffolded $\mathrm{Na}_{3} \mathrm{~V}_{2}\left(\mathrm{PO}_{4}\right)_{3}$ microsphere cathode with high rate capability and cycling stability for sodium ion batteries. ACS Appl. Mater. Interfaces 9, 7177-7184 (2017).

39. Cai, Y. et al. Caging Na3V2(PO4)2F3 microcubes in cross-linked graphene enabling ultrafast sodium storage and long-term cycling. Adv. Sci. 5, 1800680 (2018).

40. Qi, Y., Zhao, J., Yang, C., Liu, H. \& Hu, Y.-S. Comprehensive studies on the hydrothermal strategy for the synthesis of $\mathrm{Na}_{3}\left(\mathrm{VO}_{1-\mathrm{x}} \mathrm{PO}_{4}\right)_{2} \mathrm{~F}_{1+2 \mathrm{x}}(0 \leq \mathrm{x} \leq 1)$ and their Na-storage performance. Small Methods 0, 1800111 (2018).

41. Chagas, L. G., Buchholz, D., Wu, L., Vortmann, B. \& Passerini, S. Unexpected performance of layered sodium-ion cathode material in ionic liquid-based electrolyte. J. Power Sources 247, 377-383 (2014).

42. Wang, H. \& Dai, H. Strongly coupled inorganic-nano-carbon hybrid materials for energy storage. Chem. Soc. Rev. 42, 3088-3113 (2013).

43. Liang, Y., Li, Y., Wang, H. \& Dai, H. Strongly coupled inorganic/nanocarbon hybrid materials for advanced electrocatalysis. J. Am. Chem. Soc. 135, 2013-2036 (2013).

44. Winter, M., Barnett, B. \& Xu, K. Before Li Ion batteries. Chem. Rev. 118, 11433-11456 (2018)

45. Cheng, X.-B., Zhang, R., Zhao, C.-Z. \& Zhang, Q. Toward safe lithium metal anode in rechargeable batteries: a review. Chem. Rev. 117, 10403-10473 (2017)

46. Manthiram, A., Yu, X. \& Wang, S. Lithium battery chemistries enabled by solid-state electrolytes. Nat. Rev. Mater. 2, 16103 (2017).

47. Budi, A. et al. Study of the initial stage of solid electrolyte interphase formation upon chemical reaction of lithium metal and N-methyl-N-propylpyrrolidinium-bis(fluorosulfonyl)imide. J. Phys. Chem. C. 116, 19789-19797 (2012).

48. Shkrob, I. A., Marin, T. W., Zhu, Y. \& Abraham, D. P. Why Bis (fluorosulfonyl)imide Is a "Magic Anion" for electrochemistry. J. Phys. Chem. C. 118, 19661-19671 (2014).

49. Philippe, B. et al. Improved performances of nanosilicon electrodes using the salt LiFSI: a photoelectron spectroscopy study. J. Am. Chem. Soc. 135, 9829-9842 (2013)

50. Eshetu, G. G. et al. In-depth interfacial chemistry and reactivity focused investigation of lithium-imide- and lithium-imidazole-based electrolytes. ACS Appl. Mater. Interfaces 8, 16087-16100 (2016).

51. Li, Y. et al. Atomic structure of sensitive battery materials and interfaces revealed by cryo-electron microscopy. Science 358, 506 (2017).

52. Zachman, M. J., Tu, Z., Choudhury, S., Archer, L. A. \& Kourkoutis, L. F. CryoSTEM mapping of solid-liquid interfaces and dendrites in lithium-metal batteries. Nature 560, 345-349 (2018).

53. Barthen, P., Frank, W. \& Ignatiev, N. Development of low viscous ionic liquids: the dependence of the viscosity on the mass of the ions. Ionics $\mathbf{2 1}$ 149-159 (2015).

54. Sun, H. et al. Large-area supercapacitor textiles with novel hierarchical conducting structures. Adv. Mater. 28, 8431-8438 (2016).

55. He, G. \& Nazar, L. F. Crystallite size control of prussian white analogues for nonaqueous potassium-ion batteries. ACS Energy Lett. 2, 1122-1127 (2017).

\section{Acknowledgements}

Part of this work was supported by the Stanford Bits and Watts Program and gift funds. Part of this work was performed at the Stanford Nano Shared Facilities (SNSF), supported by the National Science Foundation under award ECCS-1542152.

\section{Author contributions}

H.S. and H.D. conceived the idea for the project. H.S., X.X., Y.M. and Y.K. prepared $\mathrm{Na}_{3} \mathrm{~V}_{2}\left(\mathrm{PO}_{4}\right)_{3} @$ reduced graphene oxide and $\mathrm{Na}_{3} \mathrm{~V}_{2}\left(\mathrm{PO}_{4}\right)_{2} \mathrm{~F}_{3} @$ reduced graphene oxide. $\mathrm{H}$ S., and X.X. performed electrochemical experiments. H.S., G.Z. and M.A. conducted Raman spectroscopy measurements. G.Z. and H.S. performed X-ray photoelectron spectroscopy measurements. H.S., Y.-Y.L., W.H. and M.L. performed and analyzed focused ion beam, scanning electron microscope, energy-dispersive X-ray spectroscopy, thermogravimetric analysis and X-ray diffraction measurements. J.L. and H.S. performed the inductively coupled plasma measurement. M.G., Y.Z. and H.S. performed cryogenic transmission electron microscope and scanning transmission electron microscopy measurements. M.-C.L. performed the ionic conductivity measurements. H.D. supervised the project. H.S., H.P. and H.D. prepared the manuscript. All authors participated in experimental data analysis and result discussion. 


\section{Additional information}

Supplementary Information accompanies this paper at https://doi.org/10.1038/s41467019-11102-2.

Competing interests: The authors declare no competing interests.

Reprints and permission information is available online at http://npg.nature.com/ reprintsandpermissions/

Peer review information: Nature Communications thanks Roberto Torresi and Guoxiu Wang for their contribution to the peer review of this work. Peer reviewer reports are available.

Publisher's note: Springer Nature remains neutral with regard to jurisdictional claims in published maps and institutional affiliations. (c) (i) Open Access This article is licensed under a Creative Commons Attribution 4.0 International License, which permits use, sharing, adaptation, distribution and reproduction in any medium or format, as long as you give appropriate credit to the original author(s) and the source, provide a link to the Creative Commons license, and indicate if changes were made. The images or other third party material in this article are included in the article's Creative Commons license, unless indicated otherwise in a credit line to the material. If material is not included in the article's Creative Commons license and your intended use is not permitted by statutory regulation or exceeds the permitted use, you will need to obtain permission directly from the copyright holder. To view a copy of this license, visit http://creativecommons.org/ licenses/by/4.0/.

(C) The Author(s) 2019 